\title{
Monitoring marine populations and communities: methods dealing with imperfect detectability
}

\author{
S. Katsanevakis ${ }^{1,2, *}$, A. Weber $^{3}$, C. Pipitone ${ }^{4}$, M. Leopold ${ }^{5}$, M. Cronin ${ }^{6}$, M. Scheidat ${ }^{5}$, \\ T. K. Doyle ${ }^{6}$, L. Buhl-Mortensen ${ }^{7}$, P. Buhl-Mortensen ${ }^{7}$, G. D'Anna ${ }^{4}$, I. de Boois ${ }^{5}$, \\ P. Dalpadado ${ }^{7}$, D. Damalas ${ }^{1,8}$, F. Fiorentino ${ }^{9}$, G. Garofalo ${ }^{9}$, V. M. Giacalone ${ }^{4}$, \\ K. L. Hawley ${ }^{3}$, Y. Issaris ${ }^{1}$, J. Jansen ${ }^{5}$, C. M. Knight ${ }^{3}$, L. Knittweis ${ }^{10}$, I. Kröncke ${ }^{11}$, \\ S. Mirto ${ }^{12}$, I. Muxika ${ }^{13}$, H. Reiss ${ }^{11,14}$, H. R. Skjoldal ${ }^{7}$, S. Vöge ${ }^{11}$
}

${ }^{1}$ Hellenic Centre for Marine Research (HCMR), $46.7 \mathrm{~km}$ Athens-Sounio, 19013 Anavyssos, Greece

${ }^{2}$ European Commission, JRC, IES, Water Resources Unit, Ispra (VA), Italy; ${ }^{3}$ Norwegian Institute for Water Research, Trondheim, Norway; ${ }^{4}$ CNR-IAMC, Castellammare del Golfo (TP), Italy; ${ }^{5}$ Institute for Marine Resources and Ecosystem Studies, IJmuiden, The Netherlands; ${ }^{6}$ Coastal \& Marine Research Centre, University College Cork, Ireland; ${ }^{7}$ Institute of Marine Research, Bergen, Norway; ${ }^{8}$ European Commission, JRC, IPSC, Maritime Affairs Unit, Ispra (VA), Italy; ${ }^{9}$ CNR-IAMC, UOS di Mazara del Vallo, Mazara del Vallo (TP), Italy; ${ }^{10}$ Capture Fisheries Section, Ministry for Resources and Rural Affairs, Marsaxlokk, Malta; ${ }^{11}$ Senckenberg am Meer, Marine Research Department, Wilhelmshaven, Germany; ${ }^{12}$ CNR-IAMC, UOS di Messina, Messina, Italy; ${ }^{13}$ AZTI - Tecnalia / Marine Research Division, Pasaia, Spain; ${ }^{14}$ University of Nordland, Faculty of Biosciences and Aquaculture, Bodø, Norway

\begin{abstract}
Effective monitoring of populations and communities is a prerequisite for ecosystembased management of marine areas. However, monitoring programs often neglect important sources of error and thus can lead to biased estimates, spurious conclusions and false management actions. One such source of error is 'imperfect detectability', i.e. the inability of investigators to detect all individuals or all species in a surveyed area. Although there has been great effort to develop monitoring methods that account for imperfect detectability, the application of such methods in the marine environment is not as apparent as in other systems. Plot sampling is by far the most commonly applied method for biological monitoring in the marine environment, yet it largely ignores detectability issues. However, distance sampling, mark-recapture methods, repeated presence-absence surveys for occupancy estimation, and removal methods do estimate detection probabilities and provide unbiased estimates of state variables. We review these methods and the relevant tools for their application in studies on marine populations and communities, with the aim of assisting marine biologists and managers to understand the limitations and pitfalls associated with some approaches and to select the best available methods for their monitoring needs.
\end{abstract}

KEY WORDS: Biological monitoring - Detectability · Distance sampling · Mark-recapture · Occupancy $\cdot$ Plot sampling $\cdot$ Removal methods $\cdot$ Review

\section{INTRODUCTION}

An increasing number of scientists and resource managers recognise that successful marine management approaches cannot occur without effective monitoring, evaluation and adaptation (Day 2008, Katsanevakis et al. 2011a). Solid monitoring frameworks are the foundation of adaptive management and ecosystem-based approaches, as they provide the necessary information to evaluate the performance and effectiveness of management actions (Katsanevakis et al. 2011a). In an adaptive management setting, monitoring provides the feedback loop for learning about the system in order to better achieve management objectives (Lyons et al. 2008). Beyond management applications, biological monitoring may have purely scientific objectives as it is a means to test ecological hypotheses, assess the effect 
of natural and anthropogenic pressures, and understand the function of ecosystem components and the mechanisms of ecological processes.

Monitoring can be defined as the process of gathering information about some system state variables for the purpose of assessing system state and its change over time (Yoccoz et al. 2001). The focus of biological monitoring is typically ecosystems and their components, such as habitats, populations, and communities. State variables are defined as variables describing some fundamental attribute of the system and characterizing its status. Decisions about which variable(s) to monitor are determined by the objectives of the monitoring program. State variables of interest for the monitoring of marine populations and communities include abundance, population density, biomass, population structure, biodiversity, and occupancy.

Before effective monitoring programmes are put in place, it is important to consider potential sources of error that can lead to spurious conclusions and false management actions. Estimations of state variables for populations or communities are potentially susceptible to 2 main sources of error: spatial variation and imperfect detectability (Yoccoz et al. 2001, Williams et al. 2002). The first source of error is due to the inability to survey the entire area of interest because of its large size. This requires drawing inferences about the study area based on a sample of smaller areas in which the species of interest are surveyed and counted. An appropriate sampling scheme following a formal sampling design is needed to ensure unbiased estimates of the state variables (e.g. Thompson 1992). Herein, we focus on the second source of error, which is the inability of investigators to detect all individuals or even all species in surveyed areas.

Many monitoring studies ignore or deal ineffectively with imperfect detectability (Yoccoz et al. 2001, Thompson 2004). One of the most active areas of biometric and wildlife research is the development of methods and tools to properly account for detection probability; this is reflected in the recent proliferation of literature describing these approaches and their increasing application in monitoring programs (e.g. Thompson et al. 1998, Buckland et al. 2001, 2004, Borchers et al. 2002, Williams et al. 2002, Thompson 2004, MacKenzie et al. 2006). However, the application of some of these methods in the marine environment seems to lag behind terrestrial and freshwater systems (Katsanevakis 2009).

In this article we focus on marine populations and communities, and provide a review of the available monitoring methods and tools that effectively take into account imperfect detectability. Inappropriate monitoring methods are quite often selected, which may lead to ineffective and biased assessments of the system state. Our aim is to assist marine wildlife scientists in choosing the appropriate method for their specific monitoring needs. We have also included plot sampling methods, which ignore detectability issues, in order to present current practices and cases where detectability is not an issue and to better demonstrate the conceptual shift to other improved methods.

First, we present the underlying concepts, statistics, and assumptions of each method as well as specific tools used in the marine environment ('Methods for monitoring'). Then, we review the applied monitoring approaches for each of the main marine components ('Monitoring approaches for the main marine components'). The interested reader is encouraged to consult the primary literature if intending to put any of the reviewed methods in place, as it was not feasible within the scope of this review to provide fine detail of all methods and field techniques, for every component of marine biota.

\section{METHODS FOR MONITORING}

\section{Plot sampling}

Plot sampling is a comprehensive method used mainly for abundance estimations, but also for other relevant parameters of a population, such as biomass or length-age structure. The key idea of plot sampling is to estimate population abundance by 'scaling up' the counts $(n)$ of animals from the covered (surveyed) area $\left(A_{c}\right)$ to the study area $(A)$ (Borchers et al. 2002). Hence, abundance in a study area of surface $A$ is estimated by $\hat{N}=n A / A_{\mathrm{c}}=n / P_{\mathrm{c}}$, where $P_{\mathrm{c}}=A_{\mathrm{c}} / A$ is the 'coverage probability', which is the fraction of the study area that was covered by the survey.

There are many different types of plot sampling with respect to the shape of the plot, which is usually a square, a strip, or a circle. However, all types of plot sampling are identical in terms of statistical treatment. The size of the plot sample depends on the size of the species being sampled and the relevant sampling technique (see supplement at www.int-res.com/ articles/suppl/b016p031_supp.pdf). Usually, $\leq 1 \mathrm{~m}^{2}$ is sufficient for sampling small-sized organisms. Strip transects for surveys of fish or large invertebrates by divers usually have a surface of some hundreds of square meters, while strips in trawl surveys may extend many thousands of square meters. 
In the marine environment, a wide variety of sampling devices is used for plot sampling (Table S1). These can be subdivided into in situ sampling equipment (grabs, trawls, dredges, nets; Figs. S1-S6) and imaging equipment (cameras or video recorders and underwater vehicles such as ROVs [remotely operated vehicles] or AUVs [autonomous underwater vehicles]; Fig. S7). Plot sampling with underwater visual surveys (e.g. quadrat sampling or strip transects) does not need special sampling equipment but only equipment to define the plot (a frame for quadrats; a reel and a line for strip transects) and SCUBA gear; (Figs. S10, S11, S14, S15). The choice of the appropriate technique and a suitable device depends primarily on the preferred habitat type and the characteristics of the target population or community (e.g. size, distribution of species). Regarding plot sampling of specific groups, detailed information is given in reviews and comparison studies on epibenthos (e.g. Rees et al. 2009), endobenthos (e.g. Eleftheriou \& McIntyre 2005, Rumohr 2009) and fish (e.g. Hilborn \& Walters 1992, Cheal \& Thompson 1997, Watson \& Quinn 1997) and in the following sections.

In plot sampling, the critical assumption is that all individuals present in the surveyed areas $A_{\mathrm{c}}$ are detected (or caught when referring to devices such as trawls, dredges, grabs etc.). However, this assumption cannot be tested using the survey data, and to ensure that it holds to a good approximation, additional data are needed (see following sections).

To ensure perfect detectability in underwater visual surveys with strip transects (Figs. S14 \& S16), it may be necessary to use narrow strips, which is problematic for scarce species (Burnham \& Anderson 1984, Buckland et al. 2001) and increases the variance of density estimators (Kulbicki \& Sarramégna 1999, Buckland et al. 2001). Kulbicki \& Sarramégna (1999) found that the maximum width that assures detection of all individuals may vary even for closely related fish species and may also change for a given species at various habitats. When designing a strip transect survey, it is impossible to estimate the maximum strip width for certain detection of the target species. If the assumption that all individuals present in the surveyed areas are detected is not met, there is underestimation of abundance, which is not uncommon in underwater surveys (Katsanevakis 2009).

In many cases, when the assumption of perfect detectability (or catchability) does not hold, an assumption of constant detectability is made, which allows for the estimation of relative abundance such as 'catch per unit effort' (CPUE), which is commonly used in trawl and dredge surveys. However, this as- sumption is also commonly violated. Catch rates of trawls and dredges may be quite low and variable, depending on various factors such as trawling speed, gear specifications, substrate, behaviour and life history of target species, size of the individuals, duration of the haul, time of the day, moon phase, and season (e.g. McLoughlin et al. 1991, Giguere \& Brulotte 1994, Tuck et al. 1997, Reiss et al. 2006).

For community studies, catch efficiency of the sampling device is assumed constant and common for all species. This assumption is critical because if the catch efficiency of the sampling device differs significantly between species (as e.g. found for trawls and dredges), the description of the community composition is biased.

\section{Distance sampling}

One widely used method that properly accounts for detection probability is distance sampling (Buckland et al. 2001, 2004), which may be considered as an extension of plot sampling. Distance sampling comprises a set of methods for estimating density and abundance of biological populations.

The main distance sampling methods are line transects and point transects. A standardized survey is conducted along a series of lines (in line transects) or points (in point transects) searching for the objects of interest. Objects could be either individuals or groups of individuals (termed clusters). The distance $y_{i}$ from the line or point is recorded for each animal (or cluster) detected. A detection function is fitted from the set of recorded distances, which is used to estimate the proportion of animals missed by the survey and, hence, correctly estimate abundance. Hereafter, we focus on line transect sampling, which is the most widely used distance sampling method in the marine environment (Katsanevakis 2009); more details on point transects may be found in Buckland et al. (2001).

Unlike plot sampling, distance sampling does not require all objects in the sampled plots (covered region) to be detected. If $n$ animals were detected in a distance sampling survey, then an estimation of the mean density and the total number of animals in the study area is given by $\hat{D}=n /\left(A_{\mathrm{c}} P_{\mathrm{a}}\right)$ and $\hat{N}=n /\left(P_{\mathrm{c}} P_{\mathrm{a}}\right)$ respectively, where $P_{\mathrm{a}}$ is the probability that any particular individual that was in the covered region was detected. On average, $P_{\mathrm{a}}$ is the fraction of animals in the covered region that was detected. It is assumed that the probability that an animal was in the covered region and the probability that an animal in the cov- 
ered region was actually detected are independent and common for all individuals.

The main task of the analysis of distance sampling data is to estimate the detection probability $P_{\mathrm{a}}\left(P_{\mathrm{c}}\right.$ is usually known by design). The fundamental concept behind the estimation of $P_{\mathrm{a}}$ from the distance data is straightforward, as illustrated in Fig. 1 (for line transect sampling). If all objects were detected, we would expect, on average, the histogram of the recorded distances $y_{i}$ from the line to be uniform (Fig. 1A), provided that the lines are randomly placed with respect to the location of the objects. Any decline in the numbers of recorded individuals with increasing distance reflects a decline in the probability of an individual being detected (Fig. 1B). The proportion of individuals detected, which is identical to the detection probability $P_{\mathrm{a}}$ may be estimated as the grey area of Fig. $1 \mathrm{C}$ divided by the total area under the horizontal line; a naive estimation of the curve of Fig. 1C could be made, e.g. by fitting with least squares the midpoints of each histogram class. When standardized (i.e. divided by its value at $y=0$ ), this curve is defined as the detection function $g(y)$, which gives the probability of detecting an individual that is at distance $y$ from the line. The focus of the statistical analysis of distance sampling data is the modelling of the detection function $g(y)$. The detection probability is then given by

$$
\hat{P}_{\mathrm{a}}=\frac{\int_{0}^{w} \hat{g}(y) \mathrm{d} y}{w}
$$

where $w$ is the half-width of the line transects, i.e. the maximum distance from the line up to which an individual is recorded.

The detection function is usually modelled in the general form:

$$
g(y)=\frac{\operatorname{key}(y)[1+\operatorname{series}(y)]}{\operatorname{key}(0)[1+\operatorname{series}(0)]}
$$

where $\operatorname{key}(y)$ is the key function and $\operatorname{series}(y)$ is a series expansion used to adjust the key function (Buckland et al. 2001). Various models for the key function and the series expansion are implemented in the program DISTANCE, which is the standard software used for analyzing distance sampling surveys (Buckland et al. 2001, Thomas et al. 2010). Inference might be improved in some cases by estimating a detection function $g(y, \mathbf{z})$ which apart from distance $y$ from the centreline also depends on a vector of covariates $\mathbf{z}$. The covariates may relate to the environment (e.g. habitat type, visibility, sea condition), the observer, or the individual detections (e.g. cluster size or individual size), and can be either continuous or qualitative factors. Marques \& Buckland (2003)
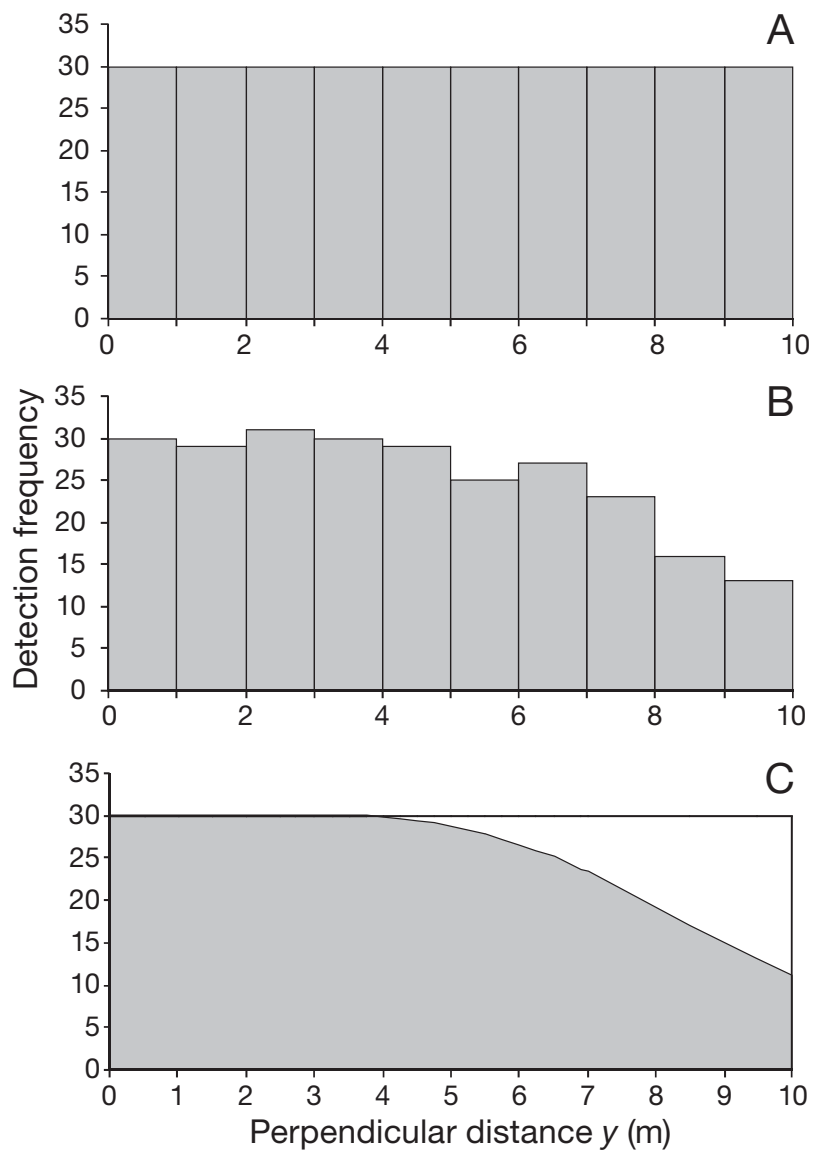

Fig. 1. (A) The expected average histogram of recorded distances, when no individuals are left undetected (or else the expected actual distribution of distances) in a line transect survey; (B) real histogram of distances, where a tendency to detect fewer individuals at greater distances is obvious; (C) a model of the distribution of distances of (B); the white area is proportional to the number of individuals that remained undetected

proposed a methodology to incorporate covariates into the estimation of the detection probabilities, which has been implemented in DISTANCE.

When the objects are detected in clusters and a count is also made of the number of individuals $\left(n_{\mathrm{cl}}\right)$ in each observed cluster, population density is estimated by

$$
\hat{D}=\frac{n}{A_{\mathrm{c}} \hat{P}_{\mathrm{a}}} \hat{E}\left(n_{\mathrm{cl}}\right)
$$

where $\hat{E}\left(n_{\mathrm{cl}}\right)$ is an estimate of the average cluster size in the population. The simplest estimate of the average cluster size is $\bar{n}_{\mathrm{cl}}$. However, as detection may be a function of cluster size, other approaches for estimating $\hat{E}\left(n_{\mathrm{cl}}\right)$ have been developed (Buckland et al. 2001).

There are 3 essential assumptions for reliable density or abundance estimations from line transect sampling (Buckland et al. 2001, Thomas et al. 2010). 
Extensions to the conventional distance sampling methods allow one or more of these assumptions to be relaxed at the expense of some extra effort during the survey (Buckland et al. 2004).

The most critical assumption is that all animals that are located on the line are detected with certainty, i.e. $g(0)=1$. In practice, detection on or near the line should be nearly certain and survey design must consider ways to assure that this assumption is met (Buckland et al. 2001). Detection probability $g(y)$ is assumed to fall off in a smooth manner out to some distance $y=w$ from the line. When the ' $g(0)=1$ ' assumption is violated, estimates of abundance are negatively biased in proportion to $g(0)$. This assumption is relaxed in mark-recapture distance sampling (Laake \& Borchers 2004).

The second basic assumption is that individuals are detected at their original location, prior to any movement in response to the observer (this is particularly important when surveying highly mobile animals such as bentho-pelagic fish or cetaceans). Random movement of animals (independently of the observer) might cause a (usually small) bias of the estimated abundance upwards because moving animals are more likely to be detected when they are close to the line, biasing detection distances down. Movement in response to the observer can cause a large bias in abundance estimation (Fewster et al. 2008). This bias will be positive if the animals are attracted by the observer, and negative if the observer is avoided. If there is undetected movement ahead of the observer and the same animal is recorded several times while traversing a single transect, bias can be quite large.

The third essential assumption is that distance measurements are exact. Although line transect estimators are fairly robust to random measurement errors, they are sensitive to systematic bias in distance measurement such as rounding to zero distance (Buckland et al. 2001, Borchers et al. 2002). Careful measurements with the use of tape lines, laser rangefinders or other means are always preferable to rough estimates by eye, which are often very poor.

Line transect surveys in the marine environment include shipboard (e.g. Southwell et al. 2004), aerial (e.g. Hammond et al. 2002, Gómez de Segura et al. 2006), and underwater surveys with snorkels or SCUBA gear (e.g. Kulbicki \& Sarramégna 1999, Katsanevakis 2009, Preuss et al. 2009) as well as with occupied submersibles (e.g. Yoklavich et al. 2007). Many different aircraft types have been used in aerial surveys, including planes (Hammond et al. 2002), helicopters (Southwell 2005), microlights (Jean et al. 2010) and blimps (Hain et al. 1999).
In shipboard surveys, animal movement prior to detection can be a problem, in particular for species that are either approaching or avoiding the vessel (e.g. Turnock \& Quinn 1991, Palka \& Hammond 2001). Field protocols should try to avoid such responsive movement, e.g. by using high-powered binoculars to detect animals before the vessel is close and triggers their response.

The ' $g(0)=1$ ' assumption is often violated in both shipboard and aerial surveys. The 2 main reasons are the availability bias (animals are there, but are not visible) and the perception bias (animals are there, but are missed by the observer). Some species spend most of their time close to the surface (e.g. Cliff 2007) or occur in shallow areas and, providing water clarity is good enough, can be recorded while they are underwater (e.g. Pollock et al. 2006). However, most marine species spend a considerable amount of time deeper in the water column and are thus not visible to an observer (not 'available'). The perception bias can be reduced by training the observers to focus their search effort on the area around the transect line (Buckland et al. 2001) and to take sufficient breaks to avoid observer fatigue. Several approaches have been taken to consider availability and perception bias and to estimate $g(0)$ in shipboard or aerial surveys. The methods include investigating breathing rates (Barlow et al. 1988), tracking animals from land concurrently with aerial surveys (Laake et al. 1997), using telemetry data (Thomsen et al. 2006), combining aerial and shipboard surveys (Palka 2005), using 2 independent observer teams on one platform (Thomsen et al. 2006), or re-surveying parts of a trackline during aerial surveys (Hiby \& Lovell 1998, Scheidat et al. 2004).

In line transect surveys by SCUBA diving, a nylon line with distance marks that is deployed using a diving reel is the most efficient way to define the transect line (Fig. S14). When surveying mobile species such as fish, the diver should be careful to satisfy the assumption of no movement in response to the observer. To satisfy this assumption, the diver should ideally move faster than the target species, and be careful to locate the point of first sighting of each individual measuring the perpendicular distance from that point to the line (Katsanevakis 2009).

\section{Repetitive surveys for occupancy estimation and modelling}

Estimation of density or abundance is often costly and requires substantial effort or may be unfeasible 
for various reasons (e.g. in the case of rare or very cryptic species). Alternatively, species occupancydefined as the proportion of area, patches, or sampling units occupied (or as the probability of presence in a sampling unit) - may be seen as a low-cost surrogate of abundance (MacKenzie et al. 2006). Moreover, there are cases when occupancy is the most appropriate state variable and would be chosen in the first place, as in studies of distribution and range (Scott et al. 2002), alien invasions (Issaris et al. 2010, Katsanevakis et al. 2011b), metapopulation studies (Moilanen 2002), community studies (Martinez-Solano et al. 2003), and large-scale monitoring (Manley et al. 2004).

By detecting a species at a sampling unit, its presence is confirmed with certainty. However, the nondetection of the species may result either from the species being genuinely absent or from the species being present at the site but undetected during the survey (MacKenzie et al. 2006). Hence, the true absence of a species from a sampling unit is often impossible to infer solely from presence-absence data. 'False absences' may lead to incorrect inferences about the system and erroneous management decisions if the imperfect detection of the species is not accounted for; occupancy is underestimated, colonization rates are biased, and habitat relationships may well be misleading, particularly if detectability also changes with habitat type (Moilanen 2002, MacKenzie 2005, MacKenzie et al. 2006).

To address this issue, a set of methods that permit inference about occupancy based on presenceabsence data while taking into account the imperfect detection of the target species has been developed (MacKenzie et al. 2006). All methods involve multiple visits to each site, and the goal is to estimate the proportion of sites that are occupied, $\psi$, accepting that the species is not always detected. Under a general sampling scheme, $s$ number of sites are surveyed for a $K$ number of times for the target species. For every survey, the appropriate methods (visual, aural, indirect traces, etc.) are used to detect the presence of at least 1 individual of the species. It is assumed that the target species is not falsely detected because of misidentification or other reasons. A site might be either occupied (with probability $\psi$ ) or unoccupied (with probability $1-\psi$ ) by the species. If the site is unoccupied, the species will not be detected. If the site is occupied, during each survey $j$ the species will either be detected (with probability $p_{j}$ ) or pass undetected (with probability $q_{j}=1-p_{j}$ ).

The series of detections and non-detections for each site is recorded as a sequence of $1 \mathrm{~s}$ and $0 \mathrm{~s}$, respectively (a detection history). For example, the probability of the detection history $H_{i}=101$ (denoting site $i$ was surveyed 3 times, with the species being detected in the first and third surveys) would be $\mathrm{P}\left(H_{i}=101\right)=\psi p_{1} q_{2} p_{3}$. For sites where the species is never detected there are 2 possibilities, either the species is present but never detected (a 'false absence') or the species is genuinely absent. Thus, $\mathrm{P}\left(H_{i}=000\right)=\psi q_{1} q_{2} q_{3}+(1-\psi)$. By deriving such expressions for each of the $s$ observed detection histories, assuming independent observations, the likelihood of the data will be

$$
L\left(\psi, \mathbf{p} \mid H_{1}, H_{2}, \ldots, H_{s}\right)=\prod_{i=1}^{s} \mathrm{P}\left(H_{i}\right)
$$

where $\mathbf{p}$ is the vector of detection probabilities.

The potential relationships between the model parameters (occupancy and detection probabilities) and characteristics of the sites (e.g. habitat type, depth, seabed slope) or environmental variables (e.g. annual average surface temperature, current intensity, water turbidity) and geographical variables (longitude, latitude) may be investigated. Covariates are incorporated by using the logistic model $\theta_{i}=\exp \left(\mathbf{Y}_{\mathbf{i}} \boldsymbol{\beta}\right)$. $\left[1+\exp \left(\mathbf{Y}_{\mathbf{i}} \boldsymbol{\beta}\right)\right]^{-1}$, where $\theta_{i}$ is the probability of interest (occupancy or detection probability), $\mathbf{Y}_{\mathbf{i}}$ are the covariates to be modelled, and $\boldsymbol{\beta}$ denotes the vector of the covariate coefficients to be estimated (MacKenzie et al. 2006). Standard maximum likelihood techniques are applied to obtain estimates of the model parameters. Occupancy models can be fitted with the software PRESENCE (Hines \& MacKenzie 2004) and MARK (White et al. 2001).

It is assumed that sites are 'closed' to changes in occupancy during the survey season, i.e. occupancy status remains constant. This may be reasonable over a relatively short time interval (e.g. within the summer period of a single year), but is unlikely to hold for longer studies. In the case of violations of the closure assumption, it is expected that the occupancy estimator will be unbiased if species move in and out of the sampling unit in a random way, although occupancy will now refer to proportions of sites 'used' by the target species (MacKenzie 2005). However, if movement in and out of the sampling unit is not random, occupancy will be biased.

In the case of unmodelled occupancy heterogeneity (variation of occupancy probability $\psi$ among sites), the bias is relatively unknown compared to other model assumptions and more simulation studies are required. Unmodelled heterogeneity in detection probability $p$ generally leads to negatively biased occupancy estimates. Low detection probabilities coupled with large variations (among sites 
or surveys) tend to increase the bias (Royle \& Nichols 2003).

Repeated surveys of the sites can be conducted as multiple discrete visits (e.g. on different days). Other options include conducting multiple surveys within a single visit; using multiple observers to conduct independent surveys, either on the same or a different visit; or surveying multiple plots within a larger site on a single visit. The decision about which approach is most practical depends upon the study objective, whether the model assumptions are likely to be satisfied given the biology of the target species, and the logistical considerations of sampling (MacKenzie \& Royle 2005). In a recent application in the marine environment, Katsanevakis et al. (2011b) studied the occupancy of benthic alien species using multiple observers (free divers) conducting independent time-limited surveys on the same visit at each site. The main benefits of that approach were cost-efficiency and improved accuracy in occupancy estimations.

In metapopulation studies or species-habitat studies, the rate of change often has a greater importance than the absolute value of the occupancy state. Multiple season occupancy models have been developed to provide estimates of rates of change or 'trends' in occupancy of target species, allowing the investigation of the effects of environmental variables and management actions by incorporating proper covariates (MacKenzie et al. 2006).

\section{Mark-recapture techniques}

Mark-recapture is a common technique used to estimate the size of populations, to study movements and migration of individuals and to provide information on birth, death and growth rates of species (Krebs 1999). Mark-recapture methods are based on capturing and marking individuals from a population and then resampling the same population to count the number of marked and unmarked individuals. The size of the entire population can be estimated from the proportions of marked and unmarked individuals. This procedure was first applied by Petersen on marine fishes and by Lincoln on waterfowl populations, and it is often referred to as the Lincoln-Peterson method (Krebs 1999). Other methods based on multiple mark-recapture samples were developed from this single mark-recapture procedure (Southwood 1978). A wide variety of indices proposed by numerous authors (reviewed by Southwood 1978 and Krebs 1999), attempted to cor- rect potential biases in estimating population sizes of the sampled taxa. Analysis of mark-recapture surveys can be conducted with the software CAPTURE (Rexstad \& Burnham 1991) and MARK (White et al. 2001).

Mark-recapture methods are valid only under certain restrictive assumptions (Southwood 1978): The first critical assumption is that animals are not affected by marks. Various marking methods have been applied to animals (Southwood 1978, Seber 1982, Nielsen 1992) but there is no perfect mark, since all tags may interfere with an animal's life cycle. For some species natural markings can be used (i.e. dorsal fins or flukes of cetaceans).

The second assumption is that there is no change in the ratio between marked and unmarked animals during the interval between samplings. This is fundamental in mark-recapture studies and, if violated, parameter estimates may be substantially biased. Studies on tag detection highlighted tag loss in several species and its effect on the estimation of population parameters (Cowen \& Schwarz 2006, De Graaf 2007). Experiments under controlled conditions have been carried out to assess tag induced mortality (Ludwig et al. 1990) and the rate of tag loss (Montgomery \& Brett 1996, Sánchez-Lamadrid 2001). The most common method to estimate rates of tag loss in the field is double tagging experiments (Barrowman \& Myers 1996). This assumption is relaxed in the Jolly-Seber method (see this section, below), which was designed for open populations and does not assume the absence of recruitment and mortality.

The third critical assumption is that all individuals have the same chance of getting caught. This assumption has 2 aspects: (1) all individuals of different age groups and of both sexes are sampled in the proportions in which they occur; (2) all individuals are equally available for capture irrespective of their location in the habitat. Moreover, the chances for each individual to be caught must remain constant during the mark-recapture period, i.e. marked individuals must not become either easier or more difficult to catch, e.g. due to a change in behaviour (Gilbert et al. 2001). Violation of this assumption due to individual heterogeneity in detection probability may induce substantial bias in the abundance estimates (Link 2003).

The fourth important assumption is that the marked animals are homogeneously distributed among the population. The time spent between the first marking and the recapture period must allow all marked individuals to disperse homogeneously throughout the population. 
The Lincoln-Peterson model is based on a single episode of marking, and a second single episode of recapturing individuals. The basic principle is that if a proportion of the population was marked in some way, returned to the original population and then, after complete mixing, a second sample was taken, the proportion of marked individuals in the second sample would be the same as was marked initially in the total population. That is, $R$ (marked recaptures) $/ C$ (total captures in second sample) = $M$ (marked initially)/ $N$ (total population size). Therefore $\hat{N}=C M / R$, where $\hat{N}$ is the estimate of population size at the time of marking.

Since the Lincoln-Peterson formula tends to overestimate the population and is based on sampling without replacement, several other formulas have been suggested to reduce the bias (Seber 1992). Several techniques of obtaining confidence intervals and accuracy for Lincoln-Peterson estimates are available (see Seber 1982, Pollock et al. 1990, Zar 1996). The Schnabel method is an extension of the LincolnPeterson model to more than 2 capture occasions (Schnabel 1938). It treats the multiple samples as a series of Lincoln-Peterson samples, and a population estimate is obtained as a weighted average of Lincoln-Peterson estimates. This method works well in closed populations such as fish in a lake.

The Jolly-Seber method (Jolly 1965, Seber 1982) considers a multiple capture-recapture survey in which there is the possibility of a gain in population numbers through recruitment or immigration, or a loss in population numbers through death or emigration. This method requires that more than 2 captures are done and that the marks, applied on one date, are different from those applied at another time. Marks identify not only that an individual has been captured previously, but also when it was first captured. As animals are tagged individually, data on movement can also be obtained simultaneously with a population estimate. The time interval between samples does not need to be constant, and any number of samples can be accommodated, so that a series of data extending over many years can be used in this method.

The assumptions of the Jolly-Seber method are: (1) probability of capture in the $t^{\text {th }}$ sample is the same for all animals (marked and unmarked); (2) probability of survival from time $t$ to $t+1$ is the same for all marked animals; (3) there are no errors in identification of individuals, and no tag losses occur; and (4) sampling time is negligible in relation to the interval between samples, i.e. the population size does not change during the sampling event. Besides popula- tion size, the Jolly-Seber method provides estimates for the probability of survival and recruitment (dilution) rate (Jolly 1965).

Despite the statistical approaches to correct the bias in estimating population size, experiments have to be carried out to evaluate some of the mark-recapture assumptions. The choice of mark or tag and of the marking or tagging procedure should be tested before conducting mark-recapture studies (Ludwig et al. 1990, Sánchez-Lamadrid 2001).

The success of the mark-recapture technique greatly depends on tools and equipment used for capturing, marking, and recapturing the specimens of a studied marine population. The sampling equipment has to be designed to collect specimens alive and in good health, thus reducing any stress prior to the marking or tagging operation. In several cases, the use of fishing equipment requires that fish be allowed to recover after tagging (Nøstvik \& Pedersen 1999).

The appropriate tag depends on the aims of the study, the size and species to tag, the shape of the individuals, their swimming speed, their habitat, the expected time between mark and recapture, and whether the tag is likely to be recovered by scientists or non-scientists. Especially with endangered species or brood stock and trophy animals, the tag must be as non-intrusive as possible. In order to reduce the stress by capture and handling, underwater tagging methods have been developed (Matthews \& Reavis 1990). Therefore, it is also appropriate to consider the ethics of acceptable practice for attaching tags (or devices) to animals (Wilson \& McMahon 2006).

Tags, internal or external, are physical devices attached to the animals' body. They sometimes protrude out of the skin and are easily visible, even underwater (Figs. S17 \& S19), so that individuals can be tracked in the field using underwater visual techniques (D'Anna \& Pipitone 2000). In recent years, electronic tags (data storage tags) have also been used to collect information on some environmental parameters that a tagged individual experiences. Marks typically infer alterations to an animal's appearance that enable the animal to be identified externally (Figs. S18 \& S20). The most common marks are: tattoos, fin clipping (partial amputation of fins), pigments, shell notches or dyes. These techniques are useful in short-term studies and restricted geographic areas. Natural markings are also commonly used for photo-identification of some marine mammals (e.g. Hammond 1986, Forcada \& Aguilar 2000; Fig. S23). 


\section{Removal methods}

The main objective of this set of methods is to estimate the abundance of animal populations. All these methods require at least 2 samplings (surveys) and are based on the following concept: following removal of a number of animals, changes in number of detections provide data that allow for estimation of the population size. It is assumed that the number of removals is known with certainty; this assumption may be violated, e.g. in the case of illegal and unreported fishing. Herein the terms 'detection', 'capture', and 'removal' may be used interchangeably.

Software to apply removal methods includes the following libraries in R: WiSp (Wildlife Simulation Package; Zucchini et al. 2007), which covers removal, catch-effort, and change-in-ratio methods through a series of functions; and FLR (Fisheries

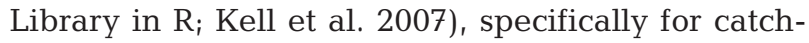
effort methods on fisheries.

\section{Simple removal}

The key idea is that, after removing a part of the population, captures will be affected, depending on the portion of removals relative to the entire original population. Assumptions underlying the method are: the population is closed, all individuals are detected (removed) with the same probability $p$ (i.e. all individuals are equally catchable), detection events are independent, detections are independent between surveys, and $p$ is the same on all occasions. In the simplest case of 2 survey occasions, a number $n_{1}$ of animals is removed (captured; detected) on a first survey, and an additional number $n_{2}$ is removed on a second survey, keeping detection probability constant. The constant detectability assumption implies that $p_{1}=p_{2}=p$, where $p_{1}=n_{1} / N$ is the detection probability during the first survey and $p_{2}=n_{2} /$ $\left(N-n_{1}\right)$ is the detection probability during the second survey. Solving these equations for $N$ and $p$ gives:

$$
\hat{N}=\frac{n_{1}^{2}}{n_{1}-n_{2}}, \quad \hat{p}=\frac{n_{1}-n_{2}}{n_{1}}
$$

In the general case of $S$ survey occasions, in which a total of $R_{s}$ animals were removed by the start of occasion $s$, the maximum likelihood estimators of $N$ and $p$ satisfy the following 2 equations (Borchers et al. 2002):

$$
\begin{gathered}
1-\frac{n}{\hat{N}}=(1-\hat{p})^{S} \\
\hat{p}=\frac{n}{\sum_{s=1}^{S}\left(\hat{N}-R_{S}\right)}
\end{gathered}
$$

For large samples and large values of $p$, assuming a normal distribution for $\hat{N}$ and $\hat{p}$, asymptotic variances of $\hat{N}$ and $\hat{p}$ are estimated as (Seber 1982):

$$
\begin{gathered}
\operatorname{Var}(\hat{N})=\frac{\hat{N}\left(1-\hat{q}^{S}\right) \hat{q}^{S}}{\left(1-\hat{q}^{S}\right)^{2}-(\hat{p} S)^{2} \hat{q}^{S-1}} \\
\operatorname{Var}(\hat{p})=\frac{(\hat{q} \hat{p})^{2}\left(1-\hat{q}^{S}\right)}{\hat{N}\left[\hat{q}\left(1-\hat{q}^{S}\right)^{2}-(\hat{p} S)^{2} \hat{q}^{S}\right]}
\end{gathered}
$$

where $\mathrm{q}=1-\mathrm{p}$.

The simple removal method is unlikely to yield good estimates when the detection probability $p$ is small. Heterogeneity in individual detection probabilities implies that the more exposed individuals are more likely to be detected. As a result, the most catchable animals will be removed first and thus average detectability of uncaught individuals will tend to decline after each removal. If the assumption of constant detectability of all individuals is violated, the abundance estimators are negatively biased. Heterogeneity of detectability among surveys can also cause large bias (Borchers et al. 2002). Simple removal methods are not commonly used in monitoring marine populations, though there are some examples, mainly for estimating fish abundance (Cowx 1983).

\section{Change-in-ratio}

The change-in-ratio method depends on the presence of observed differences in animal-level variables (size, sex, age, etc.) If there are 2 types of individuals in a population (e.g. males-females; juveniles-adults; large-small) and surveying selectively removes more of one type than the other, the calculated change-inratio allows for the estimation of population size. The underlying assumptions are that the population is closed and the 2 types of individuals are equally catchable (detection probability does not depend on the animal-level variable). The rationale applies irrespective of whether detection probabilities between the 2 occasions differ and regardless of the effort put into each survey (Borchers et al. 2002).

Basic notation used when applying the method contains the following terms: $x$ is the level variable (e.g. sex), $N$ the true population, $N_{s}(x)$ the number of animals of level $x$ in the population before survey occasion $s, N_{s}$ the population size before survey occasion $s, n_{s}$ the sample size on occasion $s, n_{s}(x)$ is the number of animals of level $x$ sampled on occasion $S_{\text {, }}$ $p_{s}(x)$ is the proportion of animals of level $x$ just before survey occasion $S_{1} R_{S}(x)$ the number of animals of level $x$ removed before survey occasion $s$, and $R_{s}$ the 
total number of animals removed before survey occasion $s$. Applying the methodology on 2 samples $(s=1$, 2) with level variable sex (m: males; f: females) we obtain that the proportion of males in the population just after the first survey is $p_{2}(m)=N_{2}(m) / N_{2}$ or

$p_{2}(m)=\frac{p_{1}(m) N_{1}-R_{2}(m)}{N_{1}-R_{2}} \Rightarrow N=N_{1}=\frac{R_{2}(m)-R_{2} p_{2}(m)}{p_{1}(m)-p_{2}(m)}$

Based on the assumption that both sexes are equally catchable:

$$
\hat{p}_{1}(m)=\frac{n_{1}(m)}{n_{1}}, \quad \hat{p}_{2}(m)=\frac{n_{2}(m)}{n_{2}}
$$

and thus

$$
\hat{N}=\frac{R_{2}(m)-R_{2} \hat{p}_{2}(m)}{\hat{p}_{1}(m)-\hat{p}_{2}(m)}
$$

Assuming that $N$ is normally distributed, we can estimate variances as (Seber 1982):

$$
\begin{gathered}
\hat{\operatorname{Var}}(\hat{N})=\frac{\sum_{s=1}^{2} \hat{N}_{s}^{2} \hat{\operatorname{Var}}\left[\hat{p}_{s}(m)\right]}{\left[\hat{p}_{1}(m)-\hat{p}_{2}(m)\right]^{2}} \\
\hat{\operatorname{Var}}\left[\hat{p}_{s}(m)\right]=\frac{\hat{p}_{s}(m)\left[1-\hat{p}_{s}(m)\right]}{\left(n_{s}-1\right)}\left(1-\frac{n_{s}}{\hat{N}_{s}}\right)
\end{gathered}
$$

Estimates of abundance are negatively biased if detection probability depends on animal-level variables, and this bias can be large. Furthermore, unless the ratio of animal types changes substantially by removal, the results can be quite unreliable (Borchers et al. 2002).

The change-in-ratio method has not been commonly used for marine populations, although it is suited in some cases, e.g. for many temperate populations of large sedentary crustaceans, particularly those subjected to fisheries of short duration (e.g. Dawe et al. 1993, Frusher et al. 2007).

\section{Catch-effort}

The concept of catch-effort method is that if more effort is put into removing animals, we would expect to remove a higher proportion of the population. The method extends the simple removal method and is generally applied in exploited populations. The key assumptions underlying the method are: the population is closed, the probability of each individual being caught with one unit of effort is constant, and all individuals have equal probability of being caught in sample $s$. If CPUE declines with time, then regressing accumulated removals upon CPUE allows for estimating the population size at the beginning of exploitation. Basic notation used for applying the methodology is: $C_{S}$ is the catch (individuals removed at sample $s$ ), $K_{s}$ is the accumulated catch just before sample $s, f_{S}$ is the effort used to obtain sample $s, \mathrm{~S}$ is the number of survey occasions, and CPUE is $C_{S} / f_{S}$.

The method is efficient only if removals are sufficient to cause a detectable decline in the CPUE. Under all the aforementioned assumptions, CPUE is proportional to the actual population size. Regressing $K_{s}$ upon CPUE gives an estimate of population size and catchability (Fig. 2). Population size $(\hat{N})$ is given by the $x$-axis intercept of the regression line, while the probability of an animal being caught in one unit of effort is given by the slope (catchability) (Krebs 1999).

In the more general case, detection probability would be an unknown function of effort $p\left(f_{s}\right)$. Functional forms for $p\left(f_{s}\right)$ are numerous and depend on the assumptions of the method used to detect animals. A common functional form used in fisheries is $p\left(f_{s}\right)=1-e^{-\theta f_{S}}$, where $\theta$ and $N$ can be estimated by maximizing the likelihood function (Borchers et al. 2002):

$$
L(N, \underline{\theta} \mid\{n, R\})=\prod_{s=1}^{S}\left(\begin{array}{l}
N_{s} \\
n_{s}
\end{array}\right) p\left(f_{s}\right)^{n_{s}}\left(1-p\left(f_{s}\right)\right)^{N_{s}-n_{s}}
$$

The catch-effort method has been applied in harvested populations for decades, especially fisheries. There are several varieties and extensions of the catch-effort method, such as biomass dynamic models (Schaefer 1954), catch-at-age methods, virtual population analysis (Gulland 1965), and Doubleday's method (Doubleday 1976). Hilborn \& Walters (1992) provide a comprehensive introduction to these methods, while Quinn \& Deriso (1999) deal with the technicalities of the statistical approaches. CPUE indices

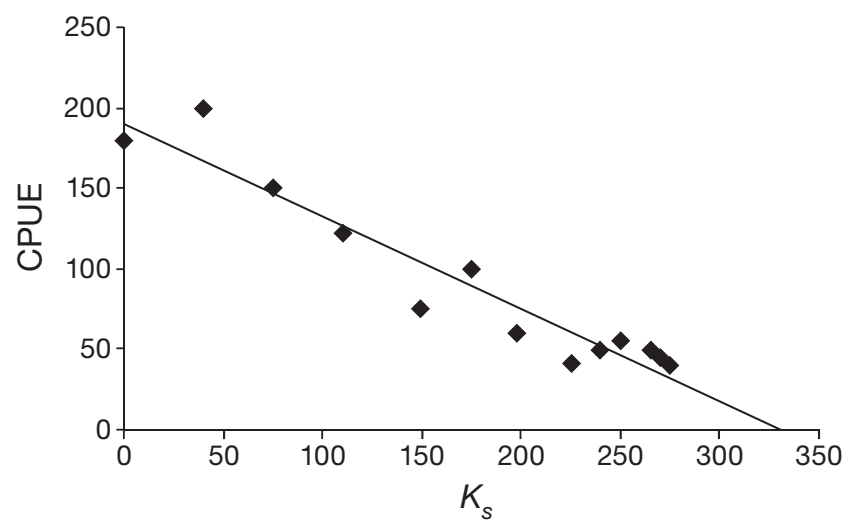

Fig. 2. Example plot of catch-effort data for a population of male blue crabs (data from Fischler 1965). CPUE: catch-perunit-effort; $K_{s}$ : accumulated catch just before sample $S$ 
have also been used for monitoring populations of marine mammals (e.g. Gales et al. 2003, NAMMCO 2006), turtles (e.g. Casale et al. 2007, Pons et al. 2010), and seabirds (e.g. Inoue et al. 2011).

CPUE from commercial surveys may give large biases if changes in catchability over time are not taken into account. There are documented cases where, although CPUE remained fairly unchanged, the population was rapidly declining. This phenomenon is called 'hyperstability' (Hilborn \& Walters 1992). Harvesting techniques become gradually more efficient and are capable of catching more animals while applying the same unit of effort. These new techniques may involve technological improvements or increases in experience. Whilst the former may be easy to detect, the latter is extremely difficult to quantify and model. In this case, officially monitored catches, when analysed, will wrongly depict a stable population status, due to the failure to incorporate in the model spatiotemporal changes in effort and catchability (but see Thorson \& Berkson 2010).

\section{MONITORING APPROACHES FOR MAIN MARINE COMPONENTS}

\section{Monitoring fish populations}

Monitoring techniques of fish populations can be split into 2 broad categories: indirect and direct methods. Indirect methods are based on fisherydependent data, such as catch and effort statistics and demographic (size and age) structure of the catch. Such methods are widely used and allow the estimation of the abundance and biomass of fish stocks at sea, either through dynamic pool methods (virtual population analysis - VPA - and its modifications) or surplus production models (Hilborn \& Walters 1992). Direct methods are based on research surveys and are aimed at avoiding the biases derived from the analysis of commercial catches. They are traditionally used to provide fishery-independent data on abundance and biomass and on the distribution by size and age of fish and shellfish. Moreover, such data are used in the 'tuning' of VPA and similar methods (Hilborn \& Walters 1992). From a different perspective, direct methods can also be split in removing (e.g. catch-based) and non-removing (e.g. acoustic or visual) methods.

Among scientific survey techniques, bottom otter trawls and beam trawls are widely used worldwide to monitor demersal fish populations, and hydroacoustic techniques are used for pelagic fish popula- tions. Due to the possibility of keeping the gear, vessel, catch processing protocols, and sampling design constant from year to year, observed changes in biological parameters, size and age structure and abundance are assumed to reflect actual changes in living populations without any bias (or with known constant bias) arising from the behaviour of fishermen.

Although trawl or dredge plot sampling surveys are valuable to monitor population trends based on time series of relative abundance indices, they may not always provide unbiased short-term abundance estimations, and they are inappropriate for many habitats such as rocky and coral reefs or seagrass meadows. Catch efficiency and selectivity issues with trawls and dredges are well documented (see 'Plot sampling'). Acoustic techniques require the collection of representative samples from the fish population for echo trace identification and, thus, matching the acoustic records to the appropriate species. The latter makes acoustic surveys impractical in areas where sample collection is difficult and in ecosystems with high species diversity, such as coral reefs.

Underwater visual surveys (UVS) for fish populations are often advantageous in certain habitats (e.g. rocky or coral reefs, seagrass beds) compared to fishing surveys. UVS are the standard monitoring tool in many cases, e.g. to monitor the ichthyofauna of coral reefs. UVS methods can involve diver-based surveys (SCUBA or snorkelling) or post hoc examination of video or photo records.

A number of biases may influence the accuracy and precision of density estimates by UVS when using plot sampling techniques. Such estimates are often confounded by imperfect detectability of individuals within the surveyed region (e.g. Thresher \& Gunn 1986, Kulbicki \& Sarramégna 1999, Edgar et al. 2004). The advantages of distance sampling methods in UVS of fish populations (accounting for detectability, providing evidence for responsive movement of fish due to the presence of the divers, applying abundance estimators with higher statistical power than plot sampling estimators) have been demonstrated in several comparative studies (e.g. Ensign et al. 1995, Kulbicki \& Sarramégna 1999). However, the mobility of fish can be a source of substantial bias in the estimation of abundance, especially movement in response to observer (Buckland et al. 2001, Fewster et al. 2008). Plot sampling (mainly strip transects) is still by far the most commonly used UVS approach for density and abundance estimations of marine fish populations, and application of distance sampling methods is rather the exception (e.g. Thresher \& Gunn 1986, Kulbicki \& Sarramégna 1999, Preuss et al. 2009). 
UVS involving SCUBA or snorkelling are restricted to shallow waters. Underwater video surveys are based on image data acquisition and have been employed to get estimates of fish abundance, diversity and size in both shallow (Willis \& Babcock 2000, Harvey et al. 2002) and deep waters (Priede \& Merrett 1998, Yau et al. 2001). But, despite the cost of ROVs and AUVs, several other constraints limit the use of video surveys to study fish populations. Low visibility and species identification requirements reduce the applicability of video surveys to a range of a few meters. Fish response to ROVs and AUVs is still poorly known and it likely affects quantitative estimates of fish. Image processing and data analysis of fish size need to be improved to obtain more accurate estimates of the demographic structure of fish populations.

During fixed-time swims or SCUBA surveys (FTS), divers do not have to follow defined transect lines but are free to record all fish encountered during a predetermined time. Such methods involve counts of fish species for a fixed duration on random paths across the selected area. The idea is that the elimination of time-consuming procedures gives the diver more time and the opportunity to detect more species (Kimmel 1985). FTS are mostly used to provide information on species composition and spatial distribution of fish assemblages but they are not recommended for the estimation of fish abundance (DeMartini \& Roberts 1982, Kimmel 1985). Rapid visual techniques (RVT) have been developedbased on successive FTS - as a low-cost and fast method to estimate species diversity and provide information on relative abundance (Kimmel 1985, Seytre \& Francour 2008). However, RVT usually over-emphasise the importance of widespread, albeit rarer species, while it underestimates patchy but abundant species as well as species diversity (DeMartini \& Roberts 1982).

Occupancy estimation based on repetitive surveys of the same sites (see 'Repetitive surveys for occupancy estimation and modelling') is a promising method for monitoring fish populations and communities, as it is a substantial improvement over simple presence-absence surveys, which often fail to provide unbiased estimates of occupancy or species richness. However, it has rarely been applied to fish monitoring (e.g. Issaris et al. 2010).

Mark-recapture techniques have been used for abundance estimations of marine fish populations (Figs. S18-S20), mainly in confined areas such as estuaries and fiords. The constraints related to markrecapture assumptions limit the applicability of the method and make it ineffective in many cases (e.g. adult fish migrating over large areas). Markrecapture has been successfully used in particular to estimate abundance, growth and survival of young sea bass (Pawson \& Eaton 1999), coral reef fish (Wormald \& Steele 2008), and to study the movements of labrids (Palmer et al. 2011) and rocky reef fish (Matthews \& Reavis 1990). Mark-recapture methods are also employed to assess the efficiency of management initiatives (i.e. fish stock enhancement, MPAs) in terms of survival, growth, and movements of fish (Brown \& Day 2002, Goñi et al. 2010).

\section{Monitoring invertebrates}

Endobenthos (soft substrata)

Methods utilized for macrofauna, meiofauna, and burrying megafauna of soft substrata include various types of grabs, corers, dredges, and benthic landers (Eleftheriou \& McIntyre 2005, Rumohr 2009) (Table S1, Figs. S1-S4). These are all plot sampling methods; for macrofauna and meiofauna no other method accounting for imperfect detectability (or catchability) has been applied. Efforts have been made by ICES to standardize the methods for monitoring macrofauna of soft substrata (Rumohr 2009). The current guidelines for quality assurance in the collection and treatment of macrofauna samples was published by ISO 16665: 2005 (ISO 2005). Indirect methods of abundance estimation based on counting burrows have been applied for some species, although there are some limitations and concerns about their reliability (e.g. McPhee \& Skilleter 2002, Butler \& Bird 2007).

Mark-recapture techniques can be applied to study growth, survival and movement of infaunal megafauna. Fluorochrome calcein has been successfully employed as a marker in numerous growth studies of mollusks, while wire markers have been used to tag bivalves (Riley et al. 2010) or to study mobility of burrowing small crabs.

\section{Epibenthos}

Epibenthos can be sampled using gears designed for macrofauna. For the larger sized epibenthic species, towed gears (trawls, dredges and sledges) are preferable (Figs. S3-S5), because they sample larger areas than grabs or corers. Other plot sampling methods include diver-operated sampling, 
camera sledges, ROVs and acoustic methods (Rees et al. 2009; Table S1).

Plot sampling is the most commonly used method to conduct UVS for estimating density and/or abundance of populations of mega-benthic invertebrates (Figs. S10, S11, S14, S15). Instead of density or abundance, the percent of species cover may be estimated for sessile species such as corals, sponges, and encrusting bryozoans. Abundance estimation of small invertebrates and analysis of community structure on rather flat surfaces may also be conducted by photo quadrats (Fig. S12) or high-resolution digital photography and digital image analysis (Pech et al. 2004). Submersibles, ROVs (Fig. S7), and drop cameras are particularly suitable for mapping and monitoring of distribution and diversity of habitats and species on hard bottom substrates below the depth of SCUBA diving. They are also suitable for description of distribution and occurrence of large and scattered organisms on soft bottoms, where sampling with other gears does not provide representative results.

Underwater distance sampling has been used to estimate population density and/or abundance of benthic invertebrates (e.g. Katsanevakis 2005, 2007, Katsanevakis \& Thessalou-Legaki 2007) (Fig. S16). Despite the advantages of distance sampling over plot sampling, the latter has been the applied method in most underwater surveys for abundance estimation of benthic invertebrates.

Occupancy estimation and modelling based on repeated surveys (sensu MacKenzie et al. 2006) has been applied lately for the study of the spatial distribution and range of alien benthic invertebrates (Issaris et al. 2010, Katsanevakis et al. 2011b). This approach proved to be an appropriate, cost-efficient, and unbiased method that improves simple presence-absence surveys.

Line intercept transect or point intercept transect surveys (Loya 1978) have been applied to estimate the percent cover of sessile species such as corals, sponges or encrusting bryozoans (e.g. Beenaerts \& Vanden Berghe 2005, Leujak \& Ormond 2007). In these methods, a transect line is laid over the bottom (usually coral or rocky reef). In line intercept transect surveys the length of line overlying various kinds of organisms is then measured. In point intercept transect surveys, the line is marked at fixed points and sessile benthic organisms or substrate categories directly beneath the marks are recorded. Line intercept transect or point intercept transect methods tend to be quicker than plot sampling methods; in comparison to quadrats they are less sensitive to small scale spatial variation (Beenaerts \& Vanden Berghe 2005).
Molluscs, echinoderms, and crustaceans are the main epibenthos taxa studied by means of markrecapture methods (Fig. S17). Among marks, quickdrying paint, adhesive tapes and plastic tags are mainly attached to molluscs, monofilament nylon is used for sea urchins, and dart tags and dyes for crustaceans (Bakus 2007). Mark-recapture techniques, including normal tagging (t-bar, spaghetti, etc.) and acoustic telemetry systems are also employed to study movement and behaviour of large crustaceans such as lobsters or crabs (Giacalone et al. 2006, Goñi et al. 2010).

\section{Hyperbenthos}

The often highly mobile hyperbenthic animals living immediately above the seabed are only occasionally collected by conventional benthic or pelagic sampling gears, thus a plethora of hyperbenthic sampling devices has been used with varying success. Sledge-mounted designs are used for sampling the hyperbenthos (Mees \& Jones 1997, Eleftheriou \& McIntyre 2005). They typically employ fine-meshed collecting nets (down to $0.5 \mathrm{~mm}$ ), flowmeters, and opening and closing mechanisms to facilitate quantification, and several of them support additional frame mounted nets to determine vertical zonation. Sledges face the same problems as all plot sampling techniques with towed gears (see 'Plot sampling'), and sledge-collected samples provide only semiquantitative abundance estimates (e.g. indices). Techniques need to be developed to effectively deal with imperfect detectability (i.e. catchability), otherwise abundance indices estimated by sledges might give misleading results due to the likely violation of the 'equal catchability' assumption.

\section{Zooplankton}

Zooplankton has been sampled using a variety of towed nets (Fig. S6) and other plot sampling techniques, such as the continuous plankton recorder (CPR) (Harris et al. 2000, Sameoto et al. 2000, Wiebe \& Benfield 2003, Richardson et al. 2006). Two major sources of error associated with zooplankton sampling are escapement or extrusion of small zooplankton forms though the mesh of the net, and avoidance of larger and more agile forms that can swim or jump away from the path of the approaching net (Sameoto et al. 2000). When standard and appropriate gear and protocols are used, plot sampling techniques can be 
adequate for relative abundance and biomass estimations of mesozooplankton communities, but catchability issues should always be of concern (Riccardi 2010).

Techniques for monitoring the abundance and distribution of gelatinous zooplankton (scyphomedusae, hydromedusae, siphonophores, and ctenophores) include various nets (Lynam et al. 2011), acoustics (Brierley et al. 2004), underwater video profilers and ROVs (Graham et al. 2003, Raskoff et al. 2005), CPR (Baxter et al. 2010), visual surface estimates from ships of opportunity and aerial surveys (Houghton et al. 2006, Bastian et al. 2011), and blue water diving (Hamner 1975). However, because jellyfish vary greatly in size (from $1 \mathrm{~mm}$ to several meters long) and are mostly fragile with distributions often over vast scales, no single method listed above is sufficient to adequately sample the entire assemblage (see Purcell 2009 for review).

\section{Monitoring marine mammals}

Distance sampling is a widely used technique for estimating the abundance of cetacean populations (Buckland et al. 1993, 2001, 2004). The primary method of distance sampling applied to cetaceans is line transect sampling (e.g. Hammond et al. 2002, Southwell et al. 2004) and cue counting, a method specifically developed for populations of large whales (Buckland et al. 2001). Various approaches have been applied to deal with perception or availability bias in distance sampling surveys (see 'Distance sampling').

Mark-recapture can be used on marine mammal species that can be identified individually (or marked individually) and that ideally aggregate in specific locations each year. For polar bears, the approach of capture, mark (e.g. ear marks or tattoos), release and recapture has been used (e.g. Gilbert 1976). A different method to identify individuals of other species is to photograph natural markings such as unique patterns on flukes or dorsal fins of cetaceans (Fig. S23) or in pinniped pelage and use those for mark-recapture calculations (Hammond 1986, Wilson et al. 1999, Forcada \& Aguilar 2000).

Migration counts are applied to large whales that migrate past coastal watch points where observers can record the animals. Correction factors then need to be applied for that proportion of the population passing outside watch hours outside the watch area. Migration counts have been used mainly for gray whales off California (e.g. Buckland et al. 1993) and bowhead whales off Alaska (e.g. George et al. 2004).
Colony counts are mainly applied to populations of pinnipeds that aggregate at terrestrial haul-out sites during certain periods of the year for breeding and moulting (Fig. S22). Counts of seals, over large areas are generally conducted by aerially acquired imagery using conventional or thermal imagery (e.g. Cronin et al. 2007) or by using a ship following the coastline (e.g. McCann \& Rothery 1988). Colony counts have also been used on sea otters (Udevitz et al. 1995). The population estimate obtained during a survey can only be considered a minimum population estimate, as a fraction of the population will be at sea and not available for counting. Minimum population estimates are sufficient for assessing long-term population trends, but an assumption must be made that the proportion of animals at sea during the count does not vary among years or geographical areas (Thompson \& Harwood 1990). Alternatively, the proportion of the population at sea during surveys can be estimated and the count corrected to obtain an estimate of absolute abundance. For example, a variety of approaches has been used to estimate this proportion for harbour seals, including telemetry (Huber et al. 2001), a bounded count method (Olesiuk et al. 1990), time lapse photography (Thompson \& Harwood 1990) and photo-identification of individuals (Moran 2003). Statistical modelling of the covariates that influence seal haul-out behaviour (e.g. weather, season, tide, time of day) can improve accuracy of counts (e.g. Cronin et al. 2010).

In the last decades, the use of acoustic monitoring methods for marine mammals has increased. Passive acoustic methods can overcome some of the limitations of visual surveys and might have a higher detection rate (e.g. Barlow \& Taylor 2005, Marques et al. 2009). Hydrophones can be towed behind a ship, the advantages being that it can be combined with visual surveys and cover large areas (e.g. Fristrup \& Clark 1997). Fixed passive acoustics can be left in an area for a prolonged period of time and such surveys are usually less expensive (Mellinger et al. 2007). Recently, new methodologies have been developed to estimate the size and density of cetacean populations by analysing data from a set of fixed passive acoustic sensors (Marques et al. 2009, 2011). These methods account for detection probabilities of acoustic cues and also for the rate at which animals produce cues, and the proportion of false positive detections.

Catch-effort methods have also been used to assess some previously exploited cetacean populations, e.g. fin whale populations in the North Atlantic within the North Atlantic Marine Mammal Commission (NAM- 
MCO 2006), or marine mammals that are caught in various fisheries as bycatch (Gales et al. 2003).

\section{Monitoring seabirds}

Several seabird species that are widely dispersed during most of the year, concentrate in few and wellknown breeding colonies in the breeding seasons. Population size (adult breeders only) and population development is often estimated by colony counts. Whole colonies, or even all colonies of a given species may be counted (Nelson 2002), or much smaller monitoring plots (plot sampling) may be followed from year to year (Walsh et al. 1995).

Ships (or small boats) may be used to get total counts of local populations, such as the number of breeding black guillemots on rocky shores (Ewins \& Tasker 1985) or flocks of seaducks in coastal waters (Leopold et al. 1995) or to map and follow populations at sea. For seabirds, the strip transect method is commonly used (e.g. Tasker et al. 1984, Komdeur et al. 1992). Often seabirds are grouped into a few predetermined, perpendicular distance bands, and an analysis similar to that of line transect data is conducted, aiming to estimate the number of nondetected seabirds. For flying birds passing through the strip, a so-called snap-shot method is used that allows estimating true densities of flying birds from a moving vessel (Tasker et al. 1984). Although distance sampling has been advocated to improve the reliability of bird surveys, vessel-based surveys for marine birds have been slow to adopt this method, with only a few exceptions (e.g. Ronconi \& Burger 2009).

Mark-recapture techniques are widely applied for monitoring and diagnosis of bird populations (SanzAguilar et al. 2010). Birds are captured (as chicks before fledging or breeding adults at the nest or with the use of mist-nets placed near the breeding colonies) and ringed (Fig. S24), usually with easily read, numbered, coloured rings. Mark-recapture surveys aim not only to provide abundance estimates, but also estimates of demographic parameters and life cycle traits such as survival, mortality rates, recruitment, breeding probabilities, migration, feeding behaviour, and territoriality (e.g. Doherty et al. 2004, Sandvik et al. 2005).

Seawatching (counting numbers of seabirds passing a vantage point on the coast per hour) is an old monitoring technique to follow numbers of seabirds over time (Waltho 2005). Long-term datasets exist for certain sites, but it is not always easy to determine which state variable is actually being monitored.
Long-term datasets also exist in some regions of fisheries bycatch data, which can be analysed by catcheffort methods (e.g. Inoue et al. 2011).

\section{Monitoring marine turtles}

Nest counts are the most universally used technique to monitor marine turtle populations (Fig. S21). Although nest counts only provide a good assessment of the number of adult females, they are the primary response variable for assessing changes in sea turtle population size (Heppell et al. 2003).

Additional methods for monitoring turtle populations include visual surveys from boats and aircraft (Marsh \& Sinclair 1989). Aerial surveys can provide important estimates of turtle populations especially at foraging grounds (Marsh \& Sinclair 1989). Both plot sampling techniques (strip transects; e.g. Cardona et al. 2005, Witt et al. 2009) or distance sampling techniques (line transects; e.g. Gómez de Segura et al. 2006, Jean et al. 2010) have been applied in such surveys. It is important to take into account that marine turtles spend more than $90 \%$ of their time underwater (Hochscheid et al. 2010) and thus to correct surface estimates of turtles, using known behavioural data collected from tracking studies (e.g. probability of detecting a turtle at the surface). Aerial surveys may only be useful if there are high densities of turtles; once densities are too low it may become difficult to detect trends.

Turtles on a nesting beach can be individually marked with small electronic PIT (passive integrated transponder) tags, which are injected into the muscle of the shoulder, remain in place for the lifetime of the turtle, and may be detected with a small handheld scanner upon return to the beach (Reina et al. 2002). Mark-recapture techniques such as PIT tagging on nesting beaches and satellite tracking of individuals can help provide important data on inter-nesting and re-migration intervals (Solow et al. 2002). Such information is critical in determining accurate population estimates and correcting beach count data. Satellite tracking can also be used to infer mortality in turtles (Hays et al. 2003). In addition to PIT tagging and satellite tagging, there are less invasive mark-recapture techniques such as photo identification that can provide information on both males and females (Schofield et al. 2008). Analysis of fisheries bycatch data and estimation of turtle CPUE has also been applied for estimations of relative abundance and bycatch mortality of marine turtles (e.g. Casale et al. 2007, Pons et al. 2010). 


\section{CONCLUDING REMARKS}

Development of methods for monitoring biological populations is a very challenging yet active area of research. The water medium often creates additional constraints for monitoring marine populations in comparison to terrestrial ones. Estimation of state variables of the target population(s) is often confounded by imperfect detectability, which-if not properly accounted for - may lead to biased estimators and misleading assessments of population status and trend. Distance sampling, mark-recapture, repetitive surveys for occupancy estimation, and removal methods are the main general statistical methods that have been developed to account for imperfect detectability; various techniques and field protocols have been developed depending on the targeted marine component (Table 1).

Table 1. Methods applied for monitoring marine populations for each of the main components of marine biota. Underlined: the most common methods for each component, ROV: remotely operated vehicle, CPUE: catch-per-unit-effort, PIT: passive integrated transponder, na: not applicable or not relevant, potential: potentially applicable

\begin{tabular}{|c|c|c|c|c|c|}
\hline Plot sampling & $\begin{array}{l}\text { Distance } \\
\text { sampling }\end{array}$ & Mark-recapture & $\begin{array}{l}\text { Repetitive surveys } \\
\text { for occupancy } \\
\text { estimation }\end{array}$ & Removal methods & Other \\
\hline \multicolumn{6}{|l|}{ Fish } \\
\hline $\begin{array}{l}\text { Trawls, dredges; } \\
\text { strip transects (divers, } \\
\text { ROVs, drop cameras) }\end{array}$ & $\begin{array}{l}\text { Line transects by } \\
\text { divers or } \\
\text { submersibles }\end{array}$ & Tagging & $\begin{array}{l}\text { By divers; based on } \\
\text { fisheries data } \\
\text { (potential) }\end{array}$ & $\frac{\frac{\text { A variety of }}{\text { methods based on }}}{\text { fisheries data }}$ & $\begin{array}{l}\text { Acoustic methods; } \\
\text { fixed-time swims, } \\
\text { rapid visual } \\
\text { techniques }\end{array}$ \\
\hline \multicolumn{6}{|l|}{ Invertebrates } \\
\hline $\begin{array}{l}\text { Endobenthos } \\
\text { Grabs, corers; dredges; } \\
\text { burrow counting }\end{array}$ & na & $\begin{array}{l}\text { Tagging of } \\
\text { megafauna } \\
\text { (mollusks, } \\
\text { crustaceans) }\end{array}$ & $\begin{array}{l}\text { Based on repetitive } \\
\text { endobenthic } \\
\text { samples (potential) }\end{array}$ & $\begin{array}{l}\text { Simple removal or } \\
\text { CPUE } \\
\text { (for megafauna) }\end{array}$ & \\
\hline $\begin{array}{l}\text { Epibenthos } \\
\text { Trawls, dredges, sledges; } \\
\frac{\text { strip transects (divers, }}{\text { ROVs, drop cameras) }} \\
\text { quadrats, photo quadrats }\end{array}$ & $\begin{array}{l}\text { Line transects by } \\
\text { divers or } \\
\text { submersibles }\end{array}$ & $\begin{array}{l}\text { Tagging (mollusks, } \\
\text { crustaceans, } \\
\text { echinoderms) }\end{array}$ & By divers & $\begin{array}{l}\text { Simple removal or } \\
\text { CPUE }\end{array}$ & $\begin{array}{l}\text { Line intercept } \\
\text { transect or point } \\
\text { intercept transect } \\
\text { surveys }\end{array}$ \\
\hline $\begin{array}{l}\text { Hyperbenthos } \\
\text { Sledge-mounted gear }\end{array}$ & na & na & $\begin{array}{l}\text { Based on repetitive } \\
\text { sledge samples } \\
\text { (potential) }\end{array}$ & CPUE & \\
\hline $\begin{array}{l}\text { Zooplankton } \\
\text { Towed nets; } \\
\text { strip transects for mega- } \\
\text { plankton (shipboard, aerial, } \\
\text { ROVs, video profilers, } \\
\text { divers) }\end{array}$ & $\begin{array}{l}\text { Shipboard line } \\
\text { transects (for } \\
\text { megaplankton) }\end{array}$ & na & $\begin{array}{l}\text { For megaplankton } \\
\text { (potential) }\end{array}$ & na & $\begin{array}{l}\text { Continuous } \\
\text { plankton recorder } \\
\text { acoustics }\end{array}$ \\
\hline \multicolumn{6}{|l|}{ Marine mammals } \\
\hline $\begin{array}{l}\text { Cetaceans } \\
\text { Shipboard or aerial strip } \\
\text { transects }\end{array}$ & $\frac{\text { Shipboard or }}{\frac{\text { aerial line }}{\text { transects }}}$ & $\begin{array}{l}\frac{\text { Photo identification }}{\text { from natural }} \\
\frac{\text { markings on flukes }}{\text { or dorsal fins }}\end{array}$ & $\begin{array}{l}\text { Shipboard or aerial } \\
\text { (potential) }\end{array}$ & $\begin{array}{l}\text { CPUE (bycatches), } \\
\text { simple removal }\end{array}$ & Migration counts \\
\hline $\begin{array}{l}\text { Pinnipeds } \\
\text { Quadrat sampling of } \\
\text { colonies }\end{array}$ & na & $\begin{array}{l}\text { Photo identification } \\
\text { from natural } \\
\text { markings in pelage }\end{array}$ & $\begin{array}{l}\text { In marine caves, } \\
\text { beaches, etc. } \\
\text { (potential) }\end{array}$ & $\begin{array}{l}\text { CPUE (bycatches), } \\
\text { simple removal }\end{array}$ & Colony counts \\
\hline \multicolumn{6}{|l|}{ Seabirds } \\
\hline $\begin{array}{l}\text { Shipboard or aerial strip } \\
\underline{\text { transects }}\end{array}$ & $\begin{array}{l}\text { Shipboard line } \\
\text { transects }\end{array}$ & Ringing & $\begin{array}{l}\text { Shipboard or aerial } \\
\text { (potential) }\end{array}$ & $\begin{array}{l}\text { CPUE (bycatches), } \\
\text { simple removal }\end{array}$ & Seawatching \\
\hline \multicolumn{6}{|l|}{ Marine turtles } \\
\hline $\begin{array}{l}\text { Shipboard or aerial strip } \\
\text { transects }\end{array}$ & $\begin{array}{l}\text { Aerial or boat } \\
\text { surveys (line } \\
\text { transects) }\end{array}$ & $\begin{array}{l}\text { PIT tagging, } \\
\text { satellite tagging }\end{array}$ & $\begin{array}{l}\text { Shipboard, aerial, or } \\
\text { diver-based } \\
\text { (potential) }\end{array}$ & $\begin{array}{l}\text { CPUE (bycatches), } \\
\text { simple removal }\end{array}$ & $\underline{\text { Nest counts }}$ \\
\hline
\end{tabular}


In practice, detectability issues are commonly ignored. Sometimes this is justified by the lack of an appropriate cost-efficient and practical method to replace existing plot sampling approaches. For example, there is yet no realistic alternative to the use of trawlers for long-term monitoring of demersal fish assemblages on the continental shelf and slope. Hence, in the absence of a viable alternative, efforts are made to standardize plot sampling surveys in order to make derived relative indices valid to detect trends. However, in many other cases researchers stick to potentially biased methods that ignore imperfect detectability, even though better alternatives have been developed. For example, underwater visual surveys for epibenthic invertebrates are still largely based on strip transects, even though methods and field protocols for line transects are well developed. Although strip transects may be sufficient in many cases (i.e. detectability is perfect), this has to be shown (e.g. through a pilot study) and not assumed a priori. Habits, convenience, and reluctance to change established protocols often delay the transition to a more robust methodology.

In many cases, appropriate methods and field techniques that properly account for imperfect detectability do not yet exist, and further research effort is needed to develop these methods. A striking example is underwater visual surveys of fish by divers. Although such surveys are widely conducted for monitoring of shallow-water ecosystems, e.g. in assessments of coastal MPAs effectiveness, a robust methodology seems to be lacking. Strip transects are often confounded by imperfect detectability of individuals within the surveyed region. However, the application of distance sampling techniques can also be problematic due to the movement of fish in response to the observers. A method that effectively confronts imperfect detectability and responsive movement remains to be developed.

Each monitoring method is based on some fundamental assumptions. The violation of these assumptions is the starting point for the development of new methods, e.g. the violation of the ' $g(0)=1$ ' assumption led to the development of 'mark-recapture distance sampling', which is now commonly applied in cetacean surveys. There is an enormous open field of research for the development of new methods to efficiently cover all components of marine biota. Innovative techniques, use of novel technology and equipment for detecting and counting individuals, and software development for the application of often complicated statistical analyses are among the future research directions to meet the challenges of imperfect detectability.

In any case, imperfect detectability should be of concern by marine ecologists and managers; critical thinking is needed when designing a monitoring survey and deciding on the methodology and field protocols. Researchers should be aware of the need to provide evidence that their approach does not suffer from bias due to imperfect and varying detectability.

Acknowledgements. This work is part of the on-going research within the EU FP7 program 'Monitoring and Evaluation of Spatially Managed Areas' (MESMA; grant no.: 226661; www.mesma.org). G. Sutton (Coastal and Marine Research Centre, UCC) provided useful comments on the manuscript. We thank 4 anonymous reviewers for their valuable comments.

\section{LITERATURE CITED}

Bakus GJ (2007) Quantitative analysis of marine biological communities: field biology and environment. John Wiley \& Sons, Hoboken, NJ

Barlow J, Taylor BL (2005) Estimates of sperm whale abundance in the northeastern temperate Pacific from a combined acoustic and visual survey. Mar Mamm Sci 21: 429-445

Barlow J, Oliver CW, Jackson TD, Taylor BL (1988) Harbor porpoise, Phocoena phocoena, abundance estimation for California, Oregon, and Washington: aerial surveys. Fish Bull 86:433-444

Barrowman NJ, Myers RA (1996) Estimating tag-shedding rates for experiments with multiple tag types. Biometrics 52:1410-1416

Bastian T, Haberlin D, Purcell J, Hays G, Davenport J, McAllen R, Doyle T (2011) Large-scale sampling reveals the spatio-temporal distributions of the jellyfish Aurelia aurita and Cyanea capillata in the Irish Sea. Mar Biol 158:2639-2652

Baxter EJ, Walne AW, Purcell JE, McAllen R, Doyle TK (2010) Identification of jellyfish from continuous plankton recorder samples. Hydrobiologia 645:193-201

Beenaerts N, Vanden Berghe E (2005) Comparative study of three transect methods to assess coral cover, richness and diversity. Western Indian Ocean J Mar Sci 4:29-37

Borchers D, Buckland S, Zucchini W (2002) Estimating animal abundance. Springer, London

Brierley AS, Axelsen BE, Boyer DC, Lynam CP and others (2004) Single-target echo detections of jellyfish. ICES J Mar Sci 61:383-393

Brown C, Day RL (2002) The future of stock enhancements: lessons for hatchery practice from conservation biology. Fish Fish 3:79-94

> Buckland ST, Breiwick JM, Cattanach KL, Laake JL (1993) Estimated population size of the California gray whale. Mar Mamm Sci 9:235-249

Buckland ST, Anderson DR, Burnham KP, Laake JL, Borchers DL, Thomas L (2001) Introduction to distance sampling: estimating abundance of biological populations. Oxford University Press, New York, NY

Buckland ST, Anderson DR, Burnham KP, Laake JL, 
Borchers DL, Thomas L (2004) Advanced distance sampling: estimating abundance of biological populations. Oxford University Press, New York

Burnham KP, Anderson DR (1984) The need for distance data in transect counts. J Wildl Manag 48:1248-1254

Butler S, Bird FL (2007) Estimating density of intertidal ghost shrimps using counts of burrow openings. Is the method reliable? Hydrobiologia 589:303-314

Cardona L, Revelles M, Carreras C, San Felix M, Gazo M, Aguilar A (2005) Western Mediterranean immature loggerhead turtles: habitat use in spring and summer assessed through satellite tracking and aerial surveys. Mar Biol 147:583-591

> Casale P, Cattarino L, Freggi D, Rocco M, Argano R (2007) Incidental catch of marine turtles by Italian trawlers and longliners in the central Mediterranean. Aquat Conserv 17:686-701

> Cheal AJ, Thompson AA (1997) Comparing visual counts of coral reef fish: implications of transect width and species selection. Mar Ecol Prog Ser 158:241-248

Cliff G (2007) Aerial census of whale sharks on the Northern KwaZulu-Natal coast, South Africa. Fish Res 84:41-46

> Cowen L, Schwarz CJ (2006) The Jolly-Seber model with tag loss. Biometrics 62:699-705

$>$ Cowx IG (1983) Review of the methods for estimating fish population size from survey removal data. Aquacult Res 14:67-82

> Cronin MA, Duck CD, Cadhla OÓ (2007) Aerial surveying of grey seal breeding colonies on the Blasket Islands, Co. Kerry, the Inishkea Group, Co. Mayo and the Donegal coast, Ireland. J Nat Conserv 15:73-83

Cronin MA, Zuur A, Ingram S, Rogan E (2010) A modeling framework to optimize timing of haul-out counts for estimating harbour seal abundance. NAMMCO Sci Publ 8: 213-226

D'Anna G, Pipitone C (2000) External tagging for underwater monitoring. In: Goñi R, Harmelin-Vivien M, Badalamenti F, Le Diréach L, Bernard G (eds) Introductory guide to methods for selected ecological studies in marine reserves. GIS Posidonie, Marseille, p 38-41

> Dawe EG, Heonig JM, Xu X (1993) Change-in-ratio and index-removal methods for population assessment and their application to snow crab (Chionoecetes opilio). Can J Fish Aquat Sci 50:1467-1476

> Day J (2008) The need and practice of monitoring, evaluating and adapting marine planning and managementlessons from the Great Barrier Reef. Mar Policy 32: 823-831

De Graaf M (2007) Tag retention, survival and growth of marron Cherax tenuimanus (Crustacea: Decapoda) marked with coded micro wire tags. Mar Freshw Res 58: 1044-1047

> DeMartini EE, Roberts D (1982) An empirical test of biases in the rapid visual technique for species-time censuses of reef fish assemblages. Mar Biol 70:129-134

> Doherty PF Jr, Schreiber EA Jr, Nichols JD, Hines JE, Link WA, Schenk GA, Schreiber RW (2004) Testing life history predictions in a long-lived seabird: a population matrix approach with improved parameter estimation. Oikos 105:606-618

Doubleday WG (1976) A least squares approach to analysing catch at age data. Int Comm Northw Atl Fish Res Bull 12:69-81

Edgar GJ, Barrett NS, Morton AJ (2004) Biases associated with the use of underwater visual census techniques to quantify the density and size-structure of fish populations. J Exp Mar Biol Ecol 308:269-290

Eleftheriou A, McIntyre AD (eds) (2005) Methods for the study of marine benthos. Blackwell, Oxford

$>$ Ensign WE, Angermeier PL, Dolloff CA (1995) Use of line transect methods to estimate abundance of benthic stream fishes. Can J Fish Aquat Sci 52:213-222

Ewins PJ, Tasker ML (1985) The breeding distribution of black guillemots Cepphus grylle in Orkney and Shetland, 1982-1984. Bird Study 32:186-193

Fewster RM, Southwell C, Borchers DL, Buckland ST, Pople AR (2008) The influence of animal mobility on the assumption of uniform distances in aerial line transect surveys. Wildl Res 35:275-288

Fischler KJ (1965) The use of catch-effort, catch-sampling, and tagging data to estimate a population of blue crabs. Trans Am Fish Soc 94:287-310

Forcada J, Aguilar A (2000) Use of photographic identification in capture-recapture studies of Mediterranean monk seals. Mar Mamm Sci 16:767-793

Fristrup KM, Clark CW (1997) Combining visual and acoustic survey data to enhance density estimation. Rep Int Whaling Comm 47:933-936

Frusher SD, Hoenig JM, Ihde T (2007) Evaluating catchability assumptions for change-in-ratio and index-removal estimators, with application to southern rock lobster. Fish Res 84:254-262

Gales NJ, Hindell MA, Kirkwood R (2003) Marine mammals: fisheries, tourism and management issues. CSIRO, Collingwood

> George JC, Zeh J, Suydam R, Clark C (2004) Abundance and population trend (1978-2001) of western Arctic bowhead whales surveyed near Barrow, Alaska. Mar Mamm Sci 20:755-773

> Giacalone VM, D'Anna G, Pipitone C, Badalamenti F (2006) Movements and residence time of spiny lobsters, Palinurus elephas, released in a marine protected area: an investigation by ultrasonic telemetry. J Mar Biol Assoc UK 86:1101-1106

Giguere M, Brulotte S (1994) Comparison of sampling techniques, video and dredge, in estimating sea scallop (Placopecten magellanicus, Gmelin) populations. J Shellfish Res 13:25-30

Gilbert DJ, McKenzie JR, Davies NM (2001) Evidence from tag recapture experiments that fish learn to avoid fishing gear. J Agric Biol Environ Stat 6:281-291

Gilbert JR (1976) Single season estimates of polar bear numbers using mark-recapture methods. Internal Report, US Fish and Wildlife Service, Anchorage, AK

Gómez de Segura A, Tomás J, Pedraza SN, Crespo EA, Raga JA (2006) Abundance and distribution of the endangered loggerhead turtle in Spanish Mediterranean waters and its conservational implications. Anim Conserv 9:199-206

> Goñi R, Hilborn R, Díaz D, Mallo S, Adlerstein S (2010) Net contribution of spillover from a marine reserve to fishery catches. Mar Ecol Prog Ser 400:233-243

Graham WM, Martin DL, Martin JC (2003) In situ quantification and analysis of large jellyfish using a novel video profiler. Mar Ecol Prog Ser 254:129-140

Gulland JA (1965) Estimation of mortality rates. Annex to Arctic Fisheries Working Group report. ICES Council Meeting papers, ICES Gadoid Fish Comm, no. 3

Hain JHW, Ellis SL, Kenney RD, Slay CK (1999) Sightability of right whales in coastal waters of the southeastern 
United States with implications for the aerial monitoring program. In: Garner GW, Amstrup SC, Laake JL, Manly BFJ, McDonald LL, Robertson DG (eds) Marine mammal survey and assessment methods. Balkema, Rotterdam, p 191-207

Hammond PS (1986) Estimating the size of naturally marked whale populations using capture-recapture techniques. Rep Int Whaling Comm 8(Spec):253-282

Hammond PS, Berggren P, Benke H, Borchers DL and others (2002) Abundance of the harbour porpoise and other cetaceans in the North Sea and adjacent waters. J Appl Ecol 41:1129-1139

> Hamner WM (1975) Underwater observations of blue-water plankton: logistics, techniques, and safety procedures for divers at sea. Limnol Oceanogr 20:1045-1051

Harris R, Wiebe P, Lenz J, Skjoldal HR, Huntley M (2000) ICES zooplankton methodology manual. Academic Press, San Diego, CA

Harvey E, Fletcher D, Shortis M (2002) Estimation of reef fish length by divers and by stereo-video: a first comparison of the accuracy and precision in the field on living fish under operational conditions. Fish Res 57:255-265

> Hays GC, Broderick AC, Godley BJ, Luschi P, Nichols WJ (2003) Satellite telemetry suggests high levels of fishinginduced mortality in marine turtles. Mar Ecol Prog Ser 262:305-309

Heppell SS, Snover ML, Crowder LB (2003) Sea turtle population ecology. In: Lutz PL, Musick JA, Wyneken J (eds) The biology of sea turtles. CRC Press, Boca Raton, FL, p 275-306

Hiby L, Lovell P (1998) Using aircraft in tandem formation to estimate abundance of harbour porpoise. Biometrics 54: 1280-1289

Hilborn R, Walters CJ (1992) Quantitative fisheries stock assessment: choice, dynamics and uncertainty. Chapman \& Hall, London

Hines JE, MacKenzie DI (2004) PRESENCE, version 2.0. Available at www.mbr-pwrc.usgs.gov/software/presence. $\mathrm{html}$

Hochscheid S, Bentivegna F, Hamza A, Hays GC (2010) When surfacers do not dive: multiple significance of extended surface times in marine turtles. J Exp Biol 213: $1328-1337$

Houghton JDR, Doyle TK, Davenport J, Hays GC (2006) Developing a simple, rapid method for identifying and monitoring jellyfish aggregations from the air. Mar Ecol Prog Ser 314:159-170

Huber HR, Jeffries SJ, Brown RF, Delong RL, Vanblaricom G (2001) Correcting aerial survey counts of harbor seals (Phoca vitulina richardii) in Washington and Oregon. Mar Mamm Sci 17:276-293

Inoue Y, Yokawa K, Minami H, Ochi D, Sato N, Katsumata N (2011) Distribution of seabird bycatch at WCPFC and the neighboring area of the southern hemisphere. Western \& Central Pacific Fisheries Commission, WCPFC-SC72011/EB-WP-07, Pohnpei

ISO (2005) Water quality - guidelines for quantitative sampling and sample processing of marine soft-bottom macrofauna. International Standard (ISO), no. 16665, Geneva

Issaris Y, Poursanidis D, Tsiamis K, Maroulakis M, Kytinou E, Katsanevakis S, Thessalou-Legaki M (2010) Occupancy estimation of hard bottom alien species in the National Marine Park of Zakynthos (NMPZ). Proc 14th Hellenic Conf Ichthyology. Hellenic Association of Ichthyologists, Piraeus, p 323-326
Jean C, Ciccione S, Ballorain K, Georges JY, Bourjea J (2010) Ultralight aircraft surveys reveal marine turtle population increases along the west coast of Reunion Island. Oryx 44:223-229

> Jolly GM (1965) Explicit estimates from capture-recapture data with both death and immigration - stochastic model. Biometrika 52:225-247

Katsanevakis S (2005) Abundance and spatial distribution of the Mediterranean scallop, Pecten jacobaeus, in a marine lake. Fish Res 76:417-429

Katsanevakis S (2007) Density surface modelling with line transect sampling as a tool for abundance estimation of marine benthic species: the Pinna nobilis example in a marine lake. Mar Biol 152:77-85

Katsanevakis S (2009) Estimating abundance of endangered marine benthic species using Distance Sampling through SCUBA diving: the Pinna nobilis (Mollusca: Bivalvia) example. In: Columbus AM, Kuznetsov L (eds) Endangered species: new research. Nova Science, New York, NY, p 81-115

Katsanevakis S, Thessalou-Legaki M (2007) First record of Alicia mirabilis (Anthozoa: Actiniaria) from the Aegean Sea and density assessment with distance sampling in a site of high abundance. Mar Biol Res 3:468-472

Katsanevakis S, Stelzenmüller V, South A, Sørensen TK and others (2011a) Ecosystem-based marine spatial management: review of concepts, policies, tools, and critical issues. Ocean Coast Manag 54:807-820

Katsanevakis S, Zenetos A, Mačič V, Beqiraj S, Poursanidis D, Kashta L (2011b) Invading the Adriatic: spatial patterns of marine alien species across the Ionian-Adriatic boundary. Aquat Biol 13:107-118

Kell LT, Mosqueira I, Grosjean P, Fromentin JM and others (2007) FLR: an open-source framework for the evaluation and development of management strategies. ICES J Mar Sci 64:640-646

Kimmel JJ (1985) A new species-time method for visual assessment of fishes and its comparison with established methods. Environ Biol Fishes 12:23-32

Komdeur J, Bertelsen J, Cracknell G (eds) (1992) Manual for aeroplane and ship surveys of waterfowl and seabirds. IWRB Special Publ No. 19, Slimbridge

Krebs CJ (1999) Ecological methodology. Addison Wesley Educational Publishers, Menlo Park, CA

Kulbicki M, Sarramégna S (1999) Comparison of density estimates derived from strip transect and distance sampling for underwater visual censuses: a case study of Chaetodontidae and Pomacanthidae. Aquat Living Resour 12:315-325

Laake JL, Borchers DL (2004) Methods for incomplete detection at distance zero. In: Buckland ST, Anderson DR, Burnham KP, Laake JL, Borchers DL, Thomas L (eds) Advanced distance sampling: estimating abundance of biological populations, 2nd edn. Oxford University Press, New York, NY, p 108-189

> Laake JL, Calambokidis J, Osmek SD, Rugh DJ (1997) Probability of detecting harbor porpoise from aerial surveys: estimating $g(0)$. J Wildl Manag 61:63-75

Leopold MF, Baptist HJM, Wolf PA, Offringa H (1995) De Zwarte Zeeëend Melanitta nigra in Nederland. Limosa 68:49-64

Leujak W, Ormond RFG (2007) Comparative accuracy and efficiency of six coral community survey methods. J Exp Mar Biol Ecol 351:168-187

> Link WA (2003) Nonidentifiability of population size from 
capture-recapture data with heterogeneous detection probabilities. Biometrics 59:1123-1130

Loya Y (1978) Plotless and transect methods. In: Stoddart DR, Johannes RE (eds) Coral reefs: research methods. UNESCO, Paris, p 197-217

Ludwig GM, Skjeveland JE, Funicelli NA (1990) Survival of Florida bay fish tagged with internally anchored spaghetti tags. Fla Sci 44:38-42

Lynam CP, Lilley MKS, Bastian T, Doyle TK, Beggs SE, Hays GC (2011) Have jellyfish in the Irish Sea benefited from climate change and overfishing? Glob Change Biol 17: 767-782

> Lyons JE, Runge MC, Laskowski HP, Kendall WL (2008) Monitoring in the context of structured decision-making and adaptive management. J Wildl Manag 72:1683-1692

MacKenzie DI (2005) Was it there? Dealing with imperfect detection for species presence/absence data. Aust NZ J Stat 47:65-74

MacKenzie DI, Royle JA (2005) Designing occupancy studies: general advice and allocating survey effort. J Appl Ecol 42:1105-1114

MacKenzie DI, Nichols JD, Royle JA, Pollock KH, Bailey LL, Hines JE (2006) Occupancy estimation and modeling. Academic Press, San Diego, CA

Manley PN, Zielinski WJ, Schlesinger MD, Mori SR (2004) Evaluation of a multiple-species approach to monitoring species at the ecoregional scale. Ecol Appl 14:296-310

> Marques FFC, Buckland ST (2003) Incorporating covariates into standard line transect analyses. Biometrics 59: 924-935

Marques TA, Thomas L, Ward J, DiMarzio N, Tyack PL (2009) Estimating cetacean population density using fixed passive acoustic sensors: an example with beaked whales. J Acoust Soc Am 125:1982-1994

Marques TA, Thomas L, Munger L, Wiggins S, Hildebrand JA (2011) Estimating North Pacific right whale (Eubalaena japonica) density using passive acoustic cue counting. Endang Species Res 13:163-172

Marsh H, Sinclair DF (1989) An experimental evaluation of dugong and sea turtles aerial survey techniques. Aust Wildl Res 16:639-650

Martinez-Solano I, Bosch J, Garcia-Paris M (2003) Demographic trends and community stability in a montane amphibian assemblage. Conserv Biol 17:238-244

Matthews KR, Reavis RH (1990) Underwater tagging and visual recapture as a technique for studying movement patterns of rockfish. Am Fish Soc Symp 7:168-172

> McCann TS, Rothery P (1988) Population size and status of the southern elephant seal (Mirounga leonina) at South Georgia, 1951-1985. Polar Biol 8:305-309

McLoughlin RJ, Young PC, Martin RB, Parslow J (1991) The Australian scallop dredge: estimates of catching efficiency and associated indirect fishing mortality. Fish Res 11:1-24

McPhee DP, Skilleter GA (2002) Aspects of the biology of the yabby Trypea australiensis (Dana) (Decapoda: Thalassinidea) and the potential of burrow counts as an indirect measure of population density. Hydrobiologia 485: 133-141

Mees J, Jones MB (1997) The hyperbenthos. Oceanogr Mar Biol Annu Rev 35:221-255

- Mellinger DK, Stafford KM, Moore SE, Dziak RP, Matsumoto $H$ (2007) An overview of fixed passive acoustic observation methods for cetaceans. Oceanography 20:36-45

Moilanen A (2002) Implications of empirical data quality to metapopulation model parameter estimation and application. Oikos 96:516-530

Montgomery SS, Brett PA (1996) Tagging eastern rock lobsters Jasus verreauxi: effectiveness of several types of tag. Fish Res 27:141-152

Moran JR (2003) Counting seals: estimating the unseen fraction using a covariate and capture-recapture model. MSc thesis, University of Alaska, Fairbanks

NAMMCO (2006) Report of the 14th meeting of the North Atlantic Marine Mammal Commission (NAMMCO) Scientific Committee, Reykjavik

Nelson JB (2002) The Atlantic Gannet, 2nd edn. Fenix Books, Great Yarmouth

Nielsen LA (1992) Methods of marking fish and shellfish. Spec Publ Am Fish Soc 23:7-14

Nøstvik F, Pedersen T (1999) Movement patterns and growth of wild and hatchery-reared cod (Gadus morhua L.) released as 1-group. In: Howell BR, Moksness E, Svåsand $\mathrm{T}$ (eds) Stock enhancement and sea ranching. Blackwell Scientific, Oxford, p 315-333

Olesiuk PF, Bigg MA, Ellis GM (1990) Recent trends in the abundance of harbour seals, Phoca vitulina, in British Columbia. Can J Fish Aquat Sci 47:992-1003

Palka D (2005) Aerial surveys in the northeast Atlantic: estimation of $g(0)$. In: Thomsen F, Ugarte F, Evans PGH (eds) Estimation of $g(0)$ in line-transect surveys of cetaceans. European Cetacean Society Newsletter No. 44, Special issue, p 25-34

Palka DL, Hammond PS (2001) Accounting for responsive movement in line transect estimates of abundance. Can J Fish Aquat Sci 58:777-787

Palmer M, Balle S, March D, Alos J, Linde M (2011) Size estimation of circular home range from fish markrelease-(single)-recapture data: case study of a small labrid targeted by recreational fishing. Mar Ecol Prog Ser 430:87-146

Pawson MG, Eaton DR (1999) The influence of a power station on the survival of juvenile sea bass in an estuarine nursery area. J Fish Biol 54:1143-1160

Pech D, Condal AR, Bourget E, Ardisson PL (2004) Abundance estimation of rocky shore invertebrates at small spatial scale by high-resolution digital photography and digital analysis. J Exp Mar Biol Ecol 299:185-199

Pollock KH, Nichols JD, Brownie C, Hines JE (1990) Statistical inference for capture-recapture experiments. Wildl Monogr 107:1-97

> Pollock K, Marsh H, Lawler IR, Alldredge MW (2006) Estimating animal abundance in heterogenous environments: an application to aerial surveys for dugongs. J Wildl Manag 70:255-262

Pons M, Domingo A, Sales G, Fiedler FN, Miller P, Giffoni B, Ortiz M (2010) Standardization of CPUE of loggerhead sea turtle (Caretta caretta) caught by pelagic longliners in the Southwestern Atlantic Ocean. Aquat Living Resour 23:65-75

> Preuss B, Pelletier D, Wantiez L, Letourneur Y and others (2009) Considering multiple-species attributes to understand better the effects of successive changes in protection status on a coral reef fish assemblage. ICES J Mar Sci 66:170-179

> Priede IG, Merrett NR (1998) The relationship between numbers of fish attracted to baited cameras and population density: studies on demersal grenadiers Coryphaenoides (Nematonurus) armatus in the abyssal NE Atlantic Ocean. Fish Res 36:133-137 
Purcell JE (2009) Extension of methods for jellyfish and ctenophore trophic ecology to large-scale research. Hydrobiologia 616:23-50

Quinn TJ, Deriso RB (1999) Quantitative fish dynamics. Oxford University Press, New York, NY

Raskoff KA, Purcell JE, Hopcroft RR (2005) Gelatinous zooplankton of the Arctic Ocean: in situ observations under the ice. Polar Biol 28:207-217

Rees HL, Bergman MJN, Birchenough SNR, Borja A and others (2009) Guidelines for the study of epibenthos of subtidal environments. ICES Tech Mar Environ Sci 42

Reina RD, Mayor PA, Spotila JR, Piedra R, Paladino FV (2002) Nesting ecology of the leatherback turtle, Dermochelys coriacea, at Parque Nacional Marino Las Baulas, Costa Rica: 1988-1989 to 1999-2000. Copeia 653-664

Reiss H, Krönke I, Ehrich S (2006) Estimating catching efficiency of a 2-m beam trawl for sampling epibenthos by removal experiments. ICES J Mar Sci 63:1453-1464

Rexstad E, Burnham KP (1991) User's guide for interactive program CAPTURE. Abundance estimation of closed populations. Colorado State University, Fort Collins, CO

Riccardi N (2010) Selectivity of plankton nets over mesozooplankton taxa: implications for abundance, biomass and diversity estimation. J Limnol 69:287-296

Richardson AJ, Walne AW, John AGW, Jonas TD and others (2006) Using continuous plankton recorder data. Prog Oceanogr 68:27-74

> Riley LW, Baker SM, Phlips EJ (2010) Self-adhesive wire markers for bivalve tag and recapture studies. Am Malacol Bull 28:183-184

Ronconi RA, Burger AE (2009) Estimating seabird densities from vessel transects: distance sampling and implications for strip transects. Aquat Biol 4:297-309

Royle JA, Nichols JD (2003) Estimating abundance from repeated presence absence data or point counts. Ecology 84:777-790

Rumohr H (2009) Soft-bottom macrofauna: collection, treatment, and quality assurance of samples. ICES Tech Mar Environ Sci 43

Sameoto D, Wiebe P, Runge J, Postel L, Dunn J, Miller C, Coombs S (2000) Collecting zooplankton. In: Harris RP, Wiebe PH, Lenz J, Skjoldal HR, Huntley M (eds) ICES zooplankton methodology manual. Academic Press, San Diego, CA, p 55-81

Sánchez-Lamadrid LA (2001) Effectiveness of four methods for tagging juveniles of farm-reared gilthead sea-bream, Sparus aurata. Fish Manag Ecol 8:271-278

Sandvik H, Erikstad KE, Barret RT, Yoccoz G (2005) The effect of climate on adult survival in five species of North Atlantic seabirds. J Anim Ecol 74:817-831

Sanz-Aguilar A, Tavecchia G, Minguez E, Massa B and others (2010) Recapture processes and biological inference in monitoring burrow-nesting seabirds. J Ornithol 151: 133-146

Schaefer MB (1954) Some aspects of the dynamics of populations important to the management of commercial marine fisheries. Inter-Am Trop Tuna Comm Bull 1:27-56

Scheidat M, Kock KH, Siebert U (2004) Summer distribution of harbour porpoise (Phocoena phocoena) in the German North Sea and Baltic Sea. J Cetacean Res Manag 6: 251-257

Schnabel ZE (1938) The estimation of the total fish population of a lake. Am Math Mon 45:348-352

Schofield G, Katselidis KA, Dimopoulos P, Pantis JD (2008) Investigating the viability of photo-identification as an objective tool to study endangered sea turtle populations. J Exp Mar Biol Ecol 360:103-108

Scott JM, Heglund PJ, Morrison ML, Haufler JB, Raphael MG, Wall WA, Samson FB (2002) Predicting species occurences. Inland Press, Washington, DC

Seber GAF (1982) The estimation of animal abundance and related parameters. Macmillan, New York, NY

Seber GAF (1992) A review of estimation of animal abundance II. Int Stat Rev 60:129-166

> Seytre C, Francour P (2008) Is the Cape Roux marine protected area (Saint-Raphaël, Mediterranean Sea) an efficient tool to sustain artisanal fisheries? First indications from visual censuses and trammel net sampling. Aquat Living Resour 21:297-305

> Solow AR, Bjorndal KA, Bolten AB (2002) Annual variation in nesting numbers of marine turtles: the effect of sea surface temperature on re-migration intervals. Ecol Lett 5: 742-746

Southwell C (2005) Response of seals and penguins to helicopter surveys over the pack ice off East Antarctica. Antarct Sci 17:328-334

- Southwell C, de la Mare B, Borchers DL, Burt L (2004) Shipboard line transect surveys of crab eater seal abundance in the pack-ice off East Antarctica: evaluation of assumptions. Mar Mamm Sci 20:602-620

Southwood TRE (1978) Ecological methods. Halsted Press, London

Tasker ML, Jones PH, Dixon TJ, Blake BF (1984) Counting seabirds at sea from ships: a review of methods employed and a suggestion for a standardized approach. Auk 101: $567-577$

Thomas L, Buckland ST, Rexstad E, Laake JL and others (2010) Distance software: design and analysis of distance sampling surveys for estimating population size. J Appl Ecol 47:5-14

> Thompson PM, Harwood J (1990) Methods for estimating the population size of common seals, Phoca vitulina. J Appl Ecol 27:924-938

Thompson SK (1992) Sampling. John Wiley \& Sons, New York

Thompson WL (ed) (2004) Sampling rare or elusive species: concepts, designs, and techniques for estimating population parameters. Island Press, Washington, DC

Thompson WL, White GC, Gowan C (1998) Monitoring vertebrate populations. Academic Press, San Diego, CA

Thomsen F, Laczny M, Piper W (2006) A recovery of harbour porpoises (Phocoena phocoena) in the southern North Sea? A case study off Eastern Frisia, Germany. Helgol Mar Res 60:189-195

Thorson JT, Berkson J (2010) Evaluating single- and multispecies procedures to estimate time-varying catchability functional parameters. Fish Res 101:38-49

Thresher RE, Gunn JS (1986) Comparative analysis of visual census techniques for highly mobile, reef-associated piscivores (Carangidae). Environ Biol Fishes 17: 93-116

> Tuck ID, Chapman CJ, Atkinson RJA, Bailey N, Smith RSM (1997) A comparison of methods for stock assessment of the Norway lobster, Nephrops norvegicus, in the Firth of Clyde. Fish Res 32:89-100

> Turnock BJ, Quinn TJ II (1991) The effect of responsive movement on abundance estimation using line transect sampling. Biometrics 47:701-715

> Udevitz MS, Bodkin JL, Costa DP (1995) Detection of sea otters in boat-based surveys of Prince William Sound, Alaska. Mar Mamm Sci 11:59-71 
Walsh PM, Halley DJ, Harris MP, del Nevo A, Sim IMW, Tasker ML (1995) Seabird monitoring handbook for Britain and Ireland. Joint Nature Conservation Committee, Peterborough

Waltho CM (2005) Seawatching: an unharnessed data source of coastal bird movements. The case for a webbased seawatching database. A discussion paper. Seabird Group Newsl 99:1-5

Watson RA, Quinn TJ II (1997) Performance of transect and point count underwater visual census methods. Ecol Modell 104:103-112

White GC, Burnham KP, Anderson DR (2001) Advanced features of Program Mark. In: Field R, Warren RJ, Okarma H, Sievert PR (eds) Wildlife, land, and people: priorities for the 21st century. Proc 2nd Int Wildl Manage Congr. The Wildlife Society, Bethesda, MD, p 368-377

Wiebe PH, Benfield MC (2003) From the Hensen Net toward four-dimensional biological oceanography. Prog Oceanogr $56: 7-136$

Williams BK, Nichols JD, Conroy MJ (2002) Analysis and management of animal populations. Academic Press, San Diego, CA

Willis TJ, Babcock C (2000) A baited underwater video system for the detection of relative density of carnivorous reef fish. Mar Freshw Res 51:755-776

Wilson B, Hammond PS, Thompson PM (1999) Estimating size and assessing trends in a coastal bottlenose dolphin

Editorial responsibility: Christine Paetzold,

Oldendorf/Luhe, Germany population. Ecol Appl 9:288-300

> Wilson RP, McMahon CR (2006) Measuring devices on wild animals: what constitutes acceptable practice? Front Ecol Environ 4:147-154

Witt MJ, Baert B, Broderick AC, Formia A and others (2009) Aerial surveying of the world's largest leatherback turtle rookery: a more effective methodology for large-scale monitoring. Biol Conserv 142:1719-1727

Wormald CL, Steele MA (2008) Testing assumptions of mark-recapture theory in the coral reef fish Lutjanus apodus. J Fish Biol 73:498-509

> Yau C, Collins MA, Bagley PM, Everson I, Nolan CP, Priede IG (2001) Estimating the abundance of Patagonian toothfish Dissostichus eleginoides using baited cameras: a preliminary study. Fish Res 51:403-412

Yoccoz NG, Nichols JD, Boulinier T (2001) Monitoring of biological diversity in space and time. Trends Ecol Evol 16:446-453

Yoklavich MM, Love MS, Forney KA (2007) A fishery-independent assessment of an overfished rockfish stock, cowcod (Sebastes levis), using direct observations from an occupied submersible. Can J Fish Aquat Sci 64:1795-1804

Zar JH (1996) Biostatistical anlalysis, 3rd edn. Prentice Hall, Upper Saddle River, NJ

Zucchini W, Borchers DL, Erdelmeier M, Rexstad E, Bishop J (2007) WiSP 1.2.4. Institut für Statistik und Ökonometrie, Georg-August-Universitat Göttingen

Submitted: October 5, 2011; Accepted: March 5, 2012 Proofs received from author(s): June 9, 2012 